\title{
Sensitivity of climate models to seasonal variability of snow-free land surface albedo
}

\author{
D. Rechid, S. Hagemann, D. Jacob
}

With 18 Figures

Received 26 April 2007; Accepted 4 November 2007; Published online 28 April 2008

(C) Springer-Verlag 2008

\begin{abstract}
Summary
The seasonal variation of snow-free land surface albedo was integrated into the land surface schemes of the global climate model ECHAM5 and the regional climate model REMO to test the sensitivity of climate models to the advanced surface albedo parameterisation. This new albedo parameterisation was developed in previous studies describing the monthly varying surface albedo fields as a function of vegetation phenology derived from MODIS data products. Three model simulations were performed in order to study the sensitivity of the simulated climate to the seasonal background albedo variations: 1 . control simulation with the old time-invariant surface background albedo, 2. experiment 1 with the new mean time-invariant surface background albedo field, 3 . experiment 2 with the monthly varying surface background albedo as a function of the leaf area index. The analysis of the simulation results demonstrates the influence of the new albedo parameterisation on the model simulations. Strong effects occur over Europe with the regional and the global model simulations responding differently to seasonal background albedo variations. In contrast to the global simulation, where the large-scale conditions are changed by the new albedo parameterisation, in the regional simulations the circulation patterns within the model domain are not influenced. Here, the external forcing via the lateral boundaries of the regional model domain suppress changes in
\end{abstract}

Correspondence: Diana Rechid, Max-Planck-Institute for Meteorology, Bundesstraße 53, 20146 Hamburg, Germany, e-mail: diana.rechid@zmaw.de the large-scale circulation that might occur without the external forcing. In the regional model simulations only local effects occur mainly during the summer season, when the vertical energy exchange at the land surface is enhanced compared to the winter season. The comparison of the regional and global simulation results over Europe reveals that the global model shows higher sensitivity to the changed albedo parameterization with respect to the simulated annual temperature and precipitation cycle than the regional model. For both the regional and the global study the temperature and precipitation deviations from the observations are larger than the differences between the three model simulations.

\section{Introduction}

The land surface albedo is an important parameter in climate modelling. It is defined by the ratio of solar radiation flux reflected at the surface to the total incoming solar radiation flux. It determines the energy budget of the earth's surface, which in turn drives the climate system. Uncertainties in surface albedo translate directly into errors in the calculation of net radiation and energy fluxes (Sellers et al. 1996a, b).

Land surface albedo is determined by the surface properties and shows not only spatial variability but also temporal variations. This can be observed by field studies (Song 1999) and examined using remotely sensed data (Zhou et al. 
2003). Over vegetated surfaces, the monthly variability of albedo is caused mainly by seasonally varying vegetation characteristics. In the study of Song (1999) the relationship between albedo and plant phenology was examined using field observations in prairie grassland and agricultural crops. The observed albedo showed clear changes during the phenology phases from green-up to peak greenness, dry down, and senescence or harvesting stage. The variability due to plant phenology is determined by the optical contrast between the vegetation canopy and the underlying soil surface. Over bright-coloured soils, vegetation cover reduces surface albedo, whereas plants on dark soils increase surface albedo.

Modelling studies have shown complex interactions between surface albedo, climate and the biosphere (Dickinson and Hanson 1984; Rowntree and Sangster 1986; Lofgren 1995). Many studies found a strong sensitivity of the climate to surface albedo variations caused by vegetation changes. The study of Berbet and Costa (2003) demonstrated that most of the spatial and seasonal variability in the simulated climate after tropical deforestation can be explained by the difference in the radiation reflected by the surface. The conversion from tropical forest to pasture grasses exposes more soil to the atmosphere. If the albedo of the exposed soil surface is different from the vegetation albedo, the seasonality in vegetation cover density causes important variations in surface albedo. Betts (2001) found that the global surface temperature change caused by vegetation changes is mainly due to surface albedo changes. Myhre and Myhre (2003) point art the uncertainty in the radiative forcing due to land-use changes and underscore the need for better data on surface albedo values regarding the effects of vegetation changes. Dirmeyer and Shukla (1994) investigated the effects of tropical deforestation on climate simulated by a general circulation model (GCM). They is found that the change in climate is strongly dependent on the change in surface albedo that accompanies deforestation. The increased surface albedo reduces the absorbed energy at the surface and decreases sensible and latent heat fluxes resulting in a reduction in convection and precipitation. In the study of Lin et al. (1996) the sensitivity of climate to seasonal surface albedo variations simu- lated by a two level GCM at a $10^{\circ}$ horizontal resolution was examined. They demonstrated the sensitivity of simulated precipitation to surface albedo variations, especially over eastern Asia and the Sahara. They also noted that precipitation decreases when the surface albedo is increased. Surface air temperature decreased over eastern Asia but increased over most of the Antarctica in July with the relationship between temperature and surface albedo variations being quite complex.

The aim of this study is to test an advanced land surface albedo parameterisation in a regional and a global climate model and to evaluate the influence of the seasonal background albedo variations in the simulated climate. This study continues work conducted in previous studies. The sensitivity of the simulated climate from the regional climate model (RCM) REMO (REgional Model: Jacob and Podzun 1997; Jacob et al. 2001) to seasonal vegetation changes was investigated in the study of Rechid and Jacob (2006). Their results showed the significant influence the monthly vanation of vegetation properties has on the simulated European climate. Vertical surface fluxes, temperature and precipitation are strongly affected. The near-surface climate becomes cooler and wetter during the growing season especially in eastern Europe and regions with a predominately continental climate.

So far, in the global climate model ECHAM5 (Roeckner et al. 2003) and the regional climate model REMO the albedo over snow-free land surfaces was prescribed using tabular values only depending on land cover type without temporal variability (Hagemann et al. 1999). In both models vegetation phenology is represented by monthly varying fields of leaf area index (LAI) and fractional vegetation cover (Roeckner et al. 2003; Rechid and Jacob 2006). These temporal varying vegetation fields are taken from a global dataset of land surface parameters called "LSPII" designed by Hagemann (2002). This dataset also includes monthly fields of background albedo. This annual albedo cycle was derived by a method designed for regions with bright soils where vegetation decreases the surface albedo. This is not appropriate for Europe, the standard region of the REMO model, where dark soils are dominant, and where vegetationlike grasses and crops increase the surface albedo. 
In the study of Rechid et al. (2007) an advanced parameterisation of the snow-free land surface albedo was developed describing the monthly varying surface albedo as a function of vegetation phenology using data products from the Moderate-Resolution Imaging Spectroradiometer (MODIS). The seasonal albedo cycle was prepared for application in climate modelling. The advanced albedo parameterisation was integrated into the land surface schemes of ECHAM5 and REMO. The purpose of this study is now to test this new albedo parameterisation and to investigate the sensitivity of the global climate simulated by ECHAM5 and the regional climate simulated by REMO to the new surface background albedo variations due to seasonal vegetation changes and to compare the regional and the global results.

The paper is organised as follows: Sect. 2 provides a short description of how the land surface characteristics in ECHAM5 and REMO are represented and a short description of the new albedo parameterisation scheme. In Sect. 3 the results of the global and in Sect. 4 the results of the regional sensitivity studies are presented. For both studies a comparison is done in Sect. 5. Here, the global and regional simulation results are also compared to observations. In Sect. 6 we provide conclusions and a short outlook.

\section{Background albedo parameterisation in ECHAM and REMO}

The GCM ECHAM5 (Roeckner et al. 2003) and the RCM REMO (REgional Model; Jacob and Podzun 1997; Jacob et al. 2001) use similar land surface schemes. The REMO RCM is based on the physical parameterisations of the ECHAM4 GCM. The land surface properties are represented by the same global dataset of land surface parameters (Hagemann et al. 1999; Hagemann 2002). The vegetation phenology is represented by monthly varying values of the leaf area index. These temporal varying vegetation fields are taken from a global dataset of land surface parameters LSPII (Hagemann 2002). The LSPII dataset is based on a global distribution of major ecosystem types (Global Land Cover Characteristics Database: GLCCD) according to a classification list of Olson (1994a, b). The Olson ecosystem types were derived from Advanced Very High Resolution Radiometer AVHRR data at $1 \mathrm{~km}$ resolution supplied by the International Geosphere-Biosphere Program (Eidenshink and Faundeen 1994) and constructed by the U.S. Geological Survey (1997, 2002). For each land cover type parameter values for background surface albedo, fractional vegetation cover, minimum and maximum leaf area index and other vegetation properties are allocated. This information is aggregated to the model grid scale averaging the vegetation parameters of all land cover types, which are located in one model grid cell. The seasonal variation of the LAI between minimum and maximum values is estimated using a global data field of the monthly growth factor, which is defined by climatologies of FPAR (fraction of absorbed photosynthetically active radiation) and 2m-temperature (Hagemann 2002). So far, in ECHAM5 and REMO the albedo over snow-free land surfaces was prescribed by tabular values only depending on land cover type without temporal variability.

The new background albedo parameterisation describes the monthly varying surface albedo as a function of vegetation phenology using data products from MODIS. The MODIS products of the white sky albedo for total shortwave broad bands and FPAR were analysed by Rechid et al. (2007) to separate the vegetation canopy albedo from the underlying soil albedo. They derived global maps of pure soil albedo and pure vegetation albedo on a $0.5^{\circ}$ regular latitude/longitude grid by re-sampling the high-resolution information from remote sensing-measured pixel level to the model grid scale and filling gaps with satellite data. These global maps show that in the northern and mid-latitudes soils are mainly darker than vegetation, whereas in the lower latitudes, especially in semi-deserts, soil albedo is mostly higher than vegetation albedo.

The global distributions of soil albedo $a_{\text {soil }}$ and vegetation albedo $a_{\text {canopy }}$ can be applied in climate modelling to describe the annual background albedo cycle $a$ as a function of the LAI (Rechid et al. 2007):

$a=a_{\text {soil }} \cdot e^{-0.5 \cdot \mathrm{LAI}}+a_{\mathrm{canopy}} \cdot\left(1-e^{-0.5 \cdot \mathrm{LAI}}\right)$

The temporal variation of snow-free surface albedo due to seasonally varying LAI was integrated into ECHAM5 and REMO. 


\section{Global simulations with ECHAM5}

\subsection{Model simulations}

Three model simulations were performed to study the sensitivity of the simulated global climate to the background surface albedo variability. The simulations are done at T63 horizontal resolution with 31 vertical levels using AMIP2 Sea Surface Temperatures (SST) (http://wwwpcmdi.llnl.gov/projects/amip/index.php) as forcing for the period 1978-1999: 1. control simulation with the currently used time-invariant surface background albedo $=$ CONT, 2. experiment with the new mean time-invariant surface background albedo field $=\mathbf{E X P 1}$, 3. experiment with the time-varying surface background albedo as a function of the leaf area index $=\mathbf{E X P 2}$.

a EXP1

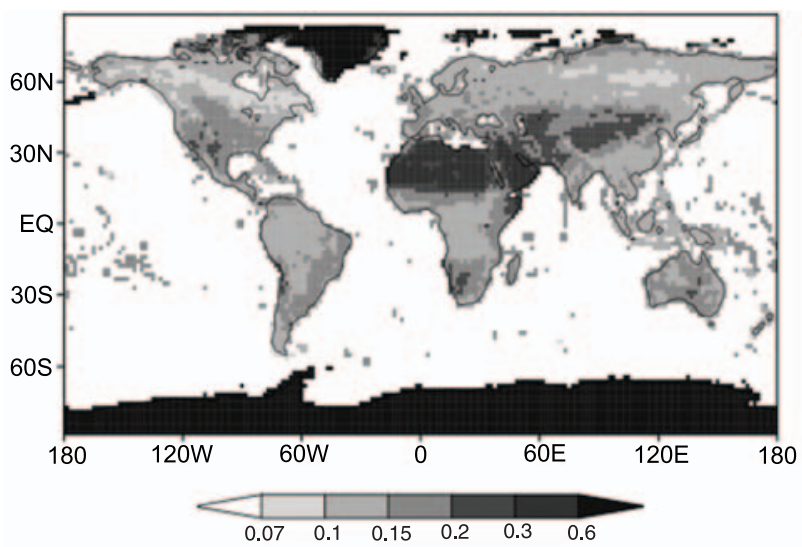

C DJF, EXP2-EXP1

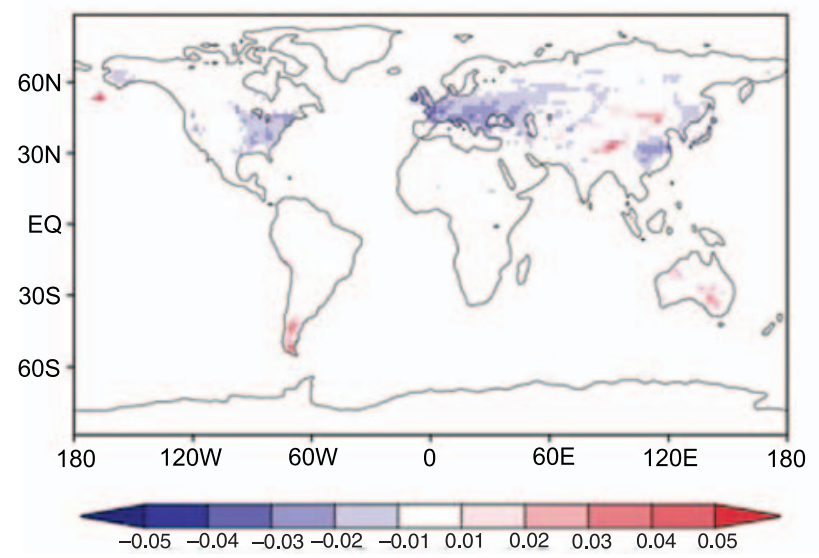

EXP1 with the new annual mean background albedo is carried out to distinguish the effect of the new mean albedo from the effect of the seasonally varying albedo on the simulation results. The horizontal distribution of the new background albedo is presented and discussed in Sect. 3.2 together with the results of the model simulation. The model results are evaluated for the 20-year time period from 1979 to 1999 skipping the first year to allow for model spin up.

\subsection{Results}

\subsubsection{Background albedo}

Figure 1a presents the horizontal distribution of the new annual mean background albedo of EXP1 and Fig. 1b the difference between the

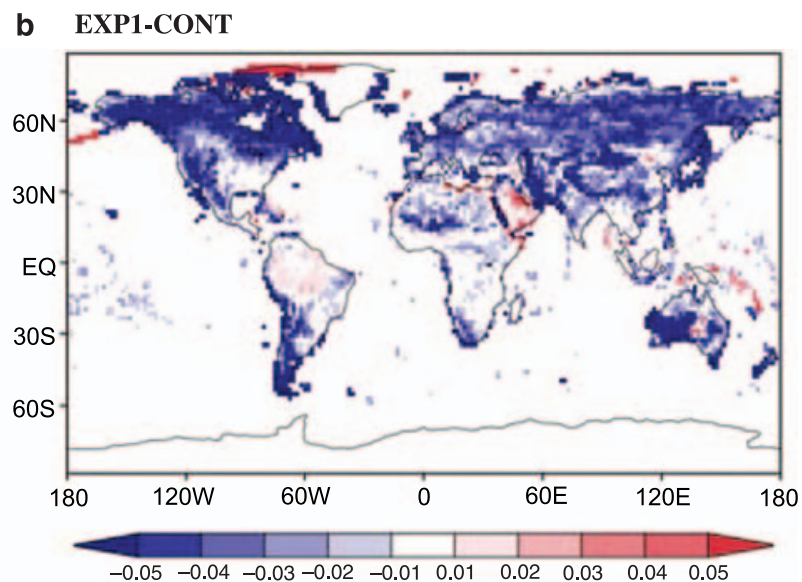

d JJA, EXP2-EXP1

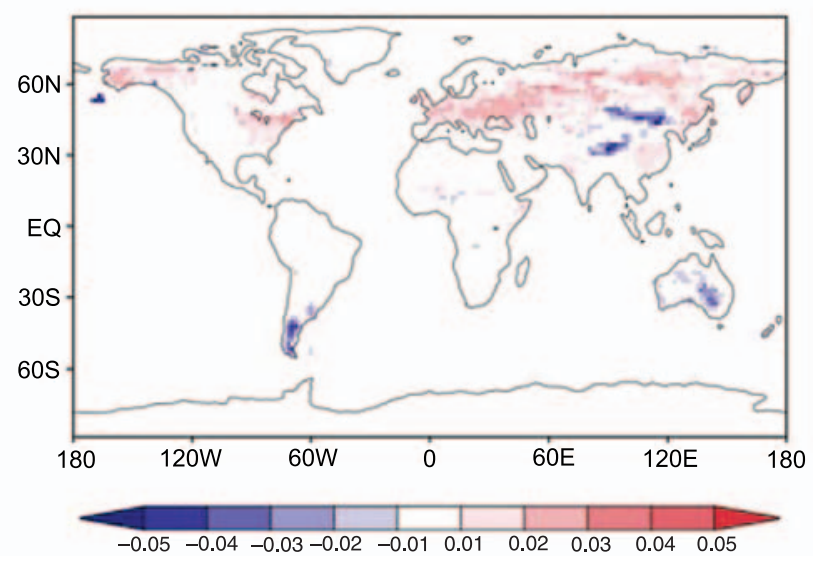

Fig. 1. New annual mean background albedo of EXP1 (a) compared to the old annual mean EXP1-CONT (b) and seasonal differences for DJF (c) and JJA (d) of temporal varying background albedo compared to the new annual mean EXP2-EXP1 1979-1999 
new and old annual mean background albedo EXP1-CONT. The new annual mean background albedo values derived from MODIS data exhibit lower values up to differences of -0.05 compared to the old annual mean albedo used in the climate model almost over the whole globe except for the Arabian Peninsula, the tropics in South America and some coastal areas. The horizontal differences caused by the seasonal background albedo variability (EXP2-EXP1) for the 20-year seasonal means of December-January-February (DJF) and June-July-August (JJA) are displayed in Fig. 1c and $\mathrm{d}$. The new annual mean background albedo leads to larger albedo differences compared to the old annual mean (EXP1-CONT) than the seasonal variations of the background albedo (EXP2EXP1). The main differences caused by the seasonal albedo variability occur in Europe, north-

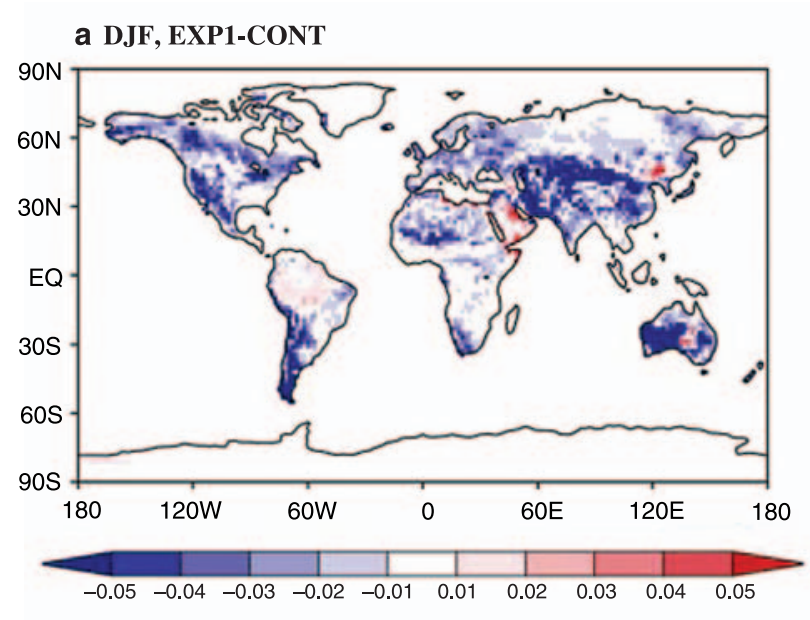

C DJF, EXP2-EXP1

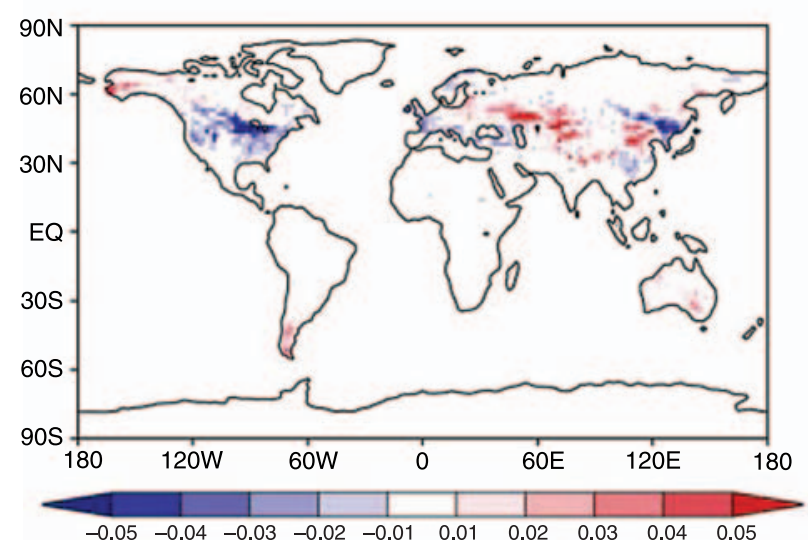

ern Asia and the eastern part of northern America with higher background albedo values during the summer season and lower values during the winter season compared to the annual mean. In these regions the soils are mainly darker than the vegetation, so that the greening up of plants during the growing season leads to higher surface albedos. In parts of eastern Asia, in Australia and in the southern part of South America, the soils are mainly brighter than the vegetation so that plants lead to decreasing albedo values.

When compared to MODIS, the mean snowfree land surface albedo is overestimated by the values of the control run. Hence, in almost all regions the new mean background albedo of Exp1 and 2 are lower than the old mean of the control run. The comparison between MODIS and the new seasonal variations indicates realistic albedo

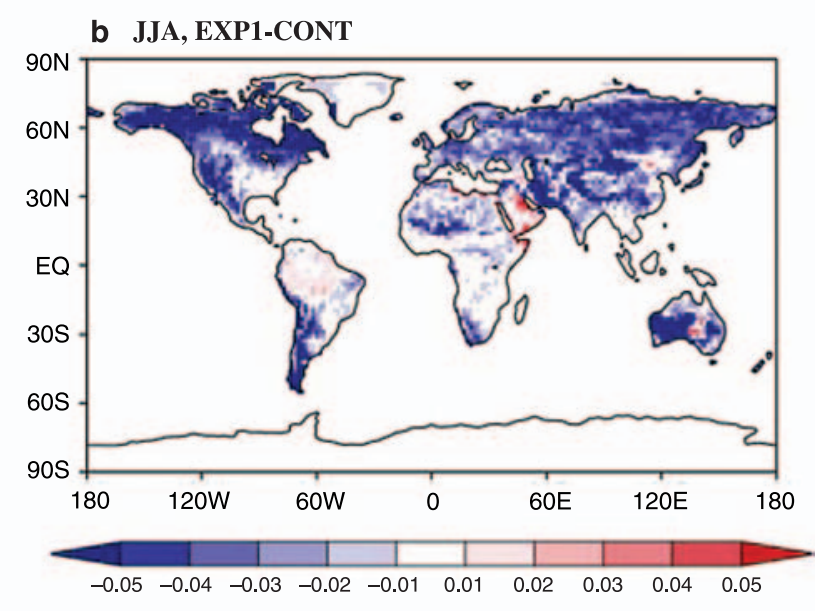

\section{d JJA, EXP2-EXP1}

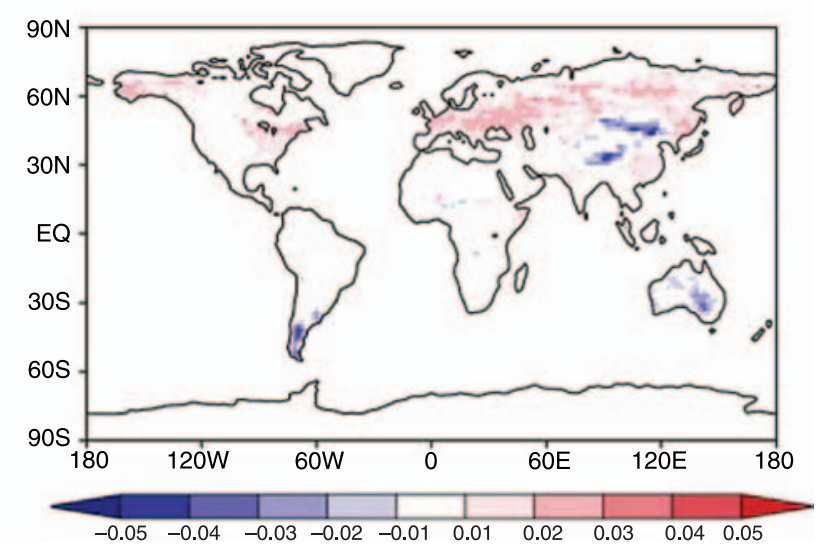

Fig. 2. Seasonal differences of the total surface albedo (including snow and water albedo) due to the new annual mean background albedo EXP1-CONT $(\mathbf{a}, \mathbf{b})$ and due to temporal varying background surface albedo EXP2-EXP1 (c, d) 1979-1999 
cycles for selected regions of the world (Rechid et al. 2007).

\subsubsection{Total surface albedo}

In the following, the horizontal differences of 20-year seasonal means for JJA and DJF between EXP1-CONT and EXP2-EXP1 are presented and discussed with the aim of separating the effects caused by the changes in mean background albedo from the effects caused by the seasonal variability of background albedo on the simulation results. The simulated total surface albedo (Fig. 2) includes albedos of water surfaces and albedos of snow covered fractions of a model grid box. The major differences again result from the new annual mean background albedo (Fig. 2a and b). In central and eastern Europe during the winter season the total surface albedo increases in EXP2 compared to EXP1 in spite of the lower back-

a DJF, EXP1-CONT

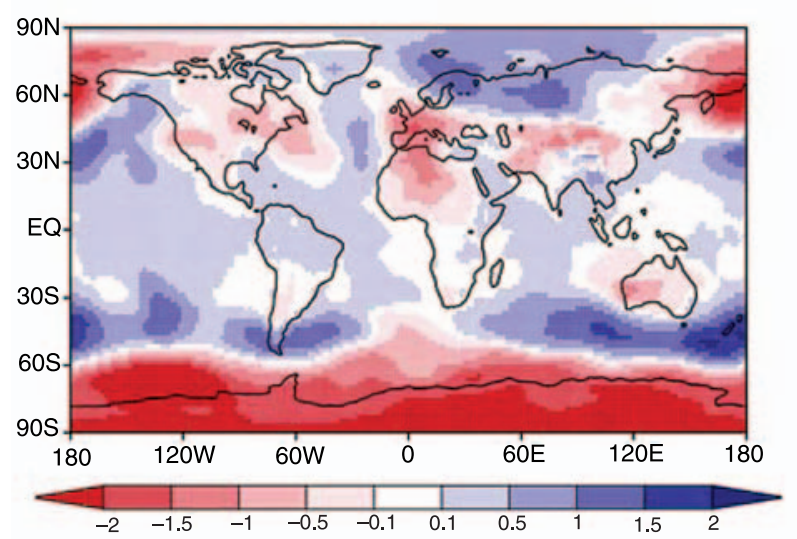

C DJF, EXP2-EXP1

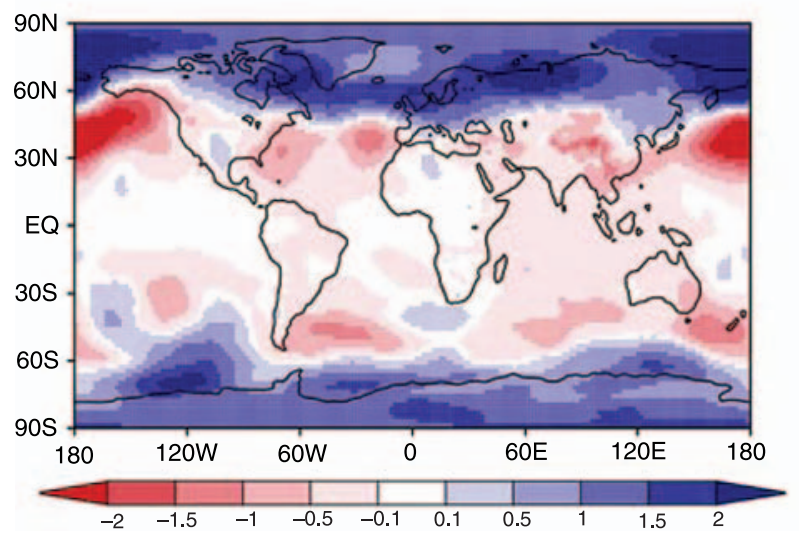

ground albedo (Fig. 2c). Here, the differences of the total albedo compared to the background albedo (compare Fig. 1c) are caused by the snow albedo which is a sign of modified snow cover conditions. During JJA (Fig. 2d) the changes in total surface albedo correspond to the seasonal background albedo variations.

\subsubsection{Mean sea-level pressure}

Simulated mean sea-level pressures show clear zonal differences for both experiments compared to the control run up to $\pm 2 \mathrm{hPa}$ (Fig. 3). Comparing EXP1 and CONT during DJF (Fig. 3a) a zonal pressure decrease up to $-2 \mathrm{hPa}$ occurs in the southern high latitudes. Over the Northern Hemisphere regional differences can be seen with a pressure decrease over central and southern Europe and northern Africa and a slight pressure increase over northern Europe and Siberia.
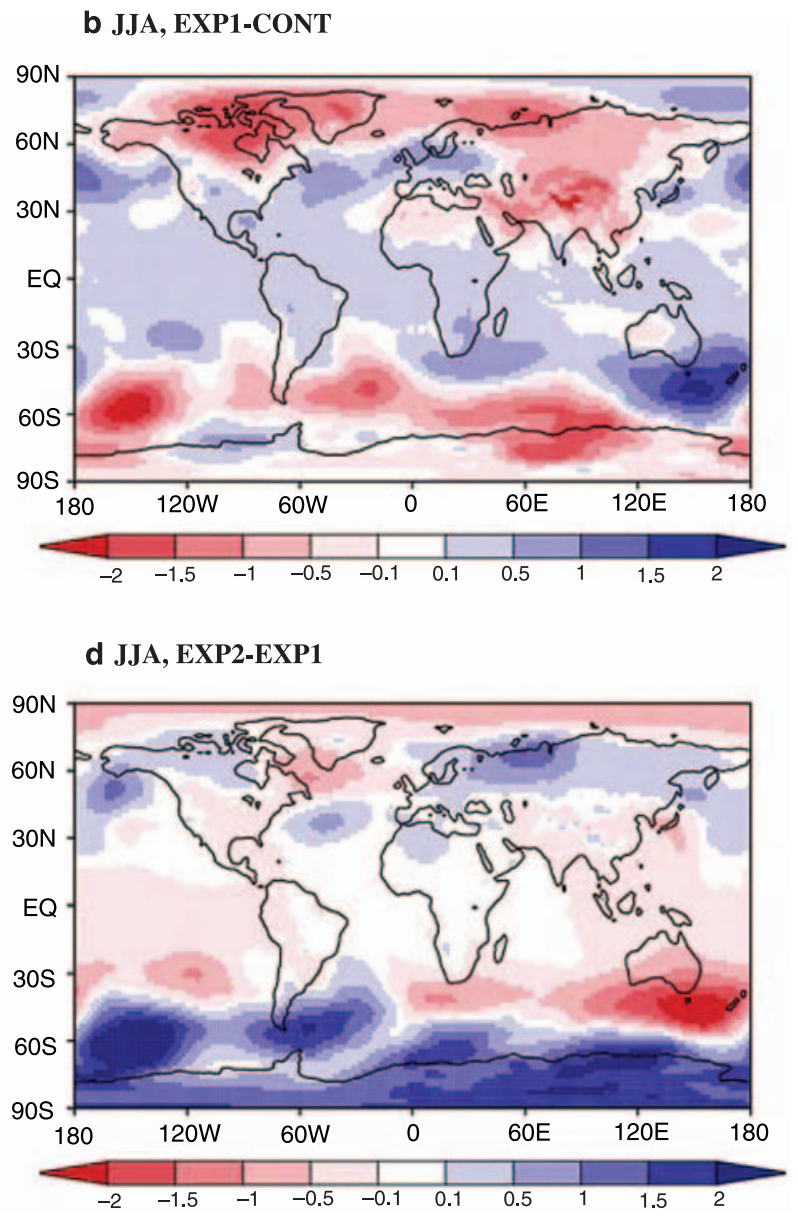

Fig. 3. Seasonal differences of mean sea-level pressure $[\mathrm{hPa}]$ due to the new annual mean background albedo EXP1-CONT (a, b) and due to temporal varying background surface albedo EXP2-EXP1 (c, d) 1979-1999 
During JJA (Fig. 3b), more regional differences occur with partly reversed conditions compared to the winter season.

In contrast, the new seasonal albedo cycle (EXP2-EXP1) leads to different patterns. Figure $3 \mathrm{c}$ shows, for DJF, a zonal increase in mean sea-level pressure up to $2 \mathrm{hPa}$ for the high latitudes whereas in the mid- and low latitudes the differences are slightly negative to zero. This can lead to modified air flows and circulation patterns. Over the Northern Atlantic, the sea-level pressure difference between the Icelandic Low and the Azores High is lower in EXP2. This lower North Atlantic Oscillation (NAO) index weakens the westerlies. For JJA (Fig. 3d) the pressure increase of $+2 \mathrm{hPa}$ only occurs in the southern high latitudes, over northern Europe and Siberia the mean pressure also increases but only regionally up to $1 \mathrm{hPa}$. Together, the moderate albedo forcing causes clear differences in mean sea-level pressure.

\subsubsection{Net surface solar radiation}

The lower mean albedo of EXP1 compared to the control simulation CONT translates directly into higher net surface solar radiation over the continents in the mid-latitudes, especially when the solar input is high during the southern summer season (Fig. 4a) and during northern summer season (Fig. 4b). In contrast, the differences in net surface solar radiation caused by the seasonal variability in background albedo are quite low. The result for DJF (Fig. 4c) and JJA (Fig. 4d) look quite patchy. In central and eastern Europe the slightly lower net surface solar radiation is caused by the higher background albedo during summer compared to the constant annual mean albedo (EXP2-EXP1). During the winter season no effect of the Northern Hemisphere seasonal albedo variability occurs due to dominating snow cover. In the Southern Hemisphere over the a DJF, EXP1-CONT

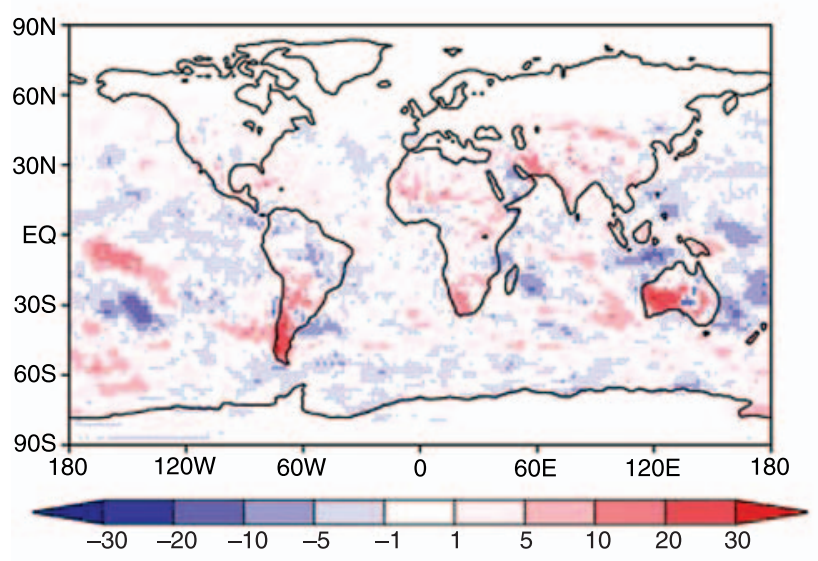

C DJF, EXP2-EXP1

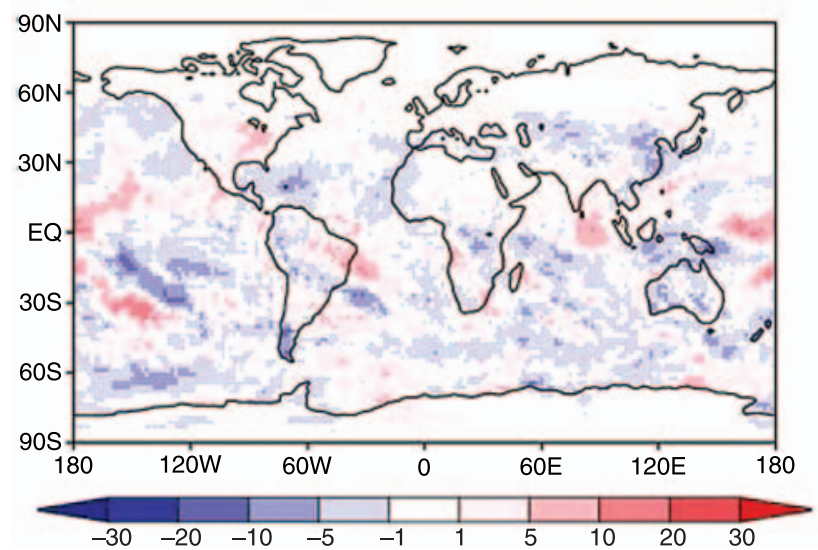

b JJA, EXP1-CONT

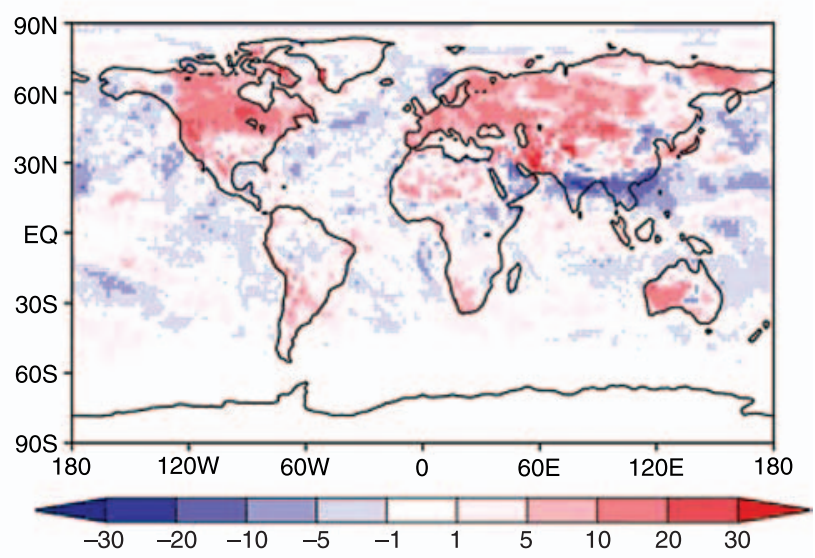

d JJA, EXP2-EXP1

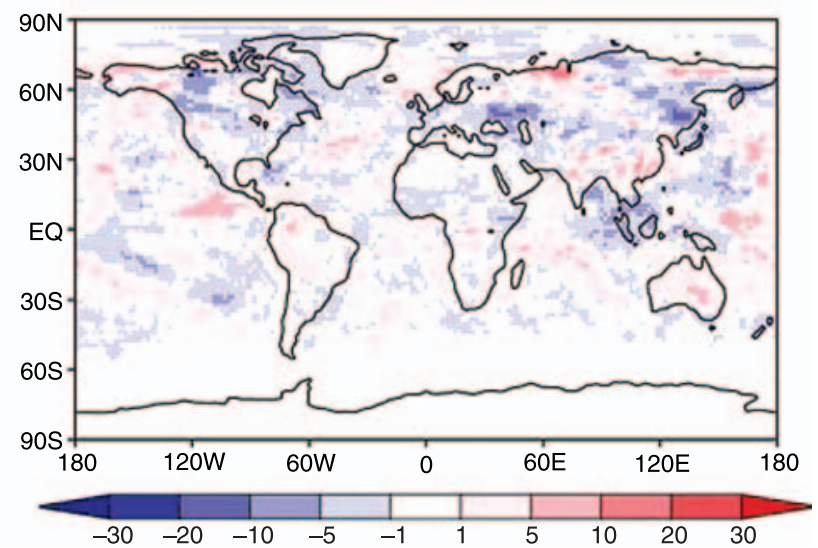

Fig. 4. Seasonal differences of net surface solar radiation $\left[\mathrm{W} / \mathrm{m}^{2}\right]$ due to the new annual mean background albedo EXP1CONT (a, b) and due to temporal varying background surface albedo EXP2-EXP1 (c, d) 1979-1999 
Pacific between $30^{\circ} \mathrm{S}$ and the Equator, and between $90^{\circ} \mathrm{W}$ and $180^{\circ} \mathrm{W}$ the net surface solar radiation is noticeably changed in DJF. The difference between EXP1 and CONT (Fig. 4a) shows an increase in seasonal net surface solar radiation in the northern part and a decrease in the southern part of this region. For EXP2-EXP1 (Fig. 4c) the reverse effect occurs. Over the regions with lower net surface solar radiation the total cloud cover is increased up to $+5 \%$ and over the regions with higher net surface solar radiation the total cloud cover is decreased up to $-5 \%$ (not shown). The seasonal precipitation changes (presented in Sect. 3.2.6 in more detail) show the same pattern. Over the region with lower net surface solar radiation and higher cloud cover to precipitation is increased up to $+40 \%$ and vice versa. These are the remote effects of the changes in land surface albedo, which indicate a modification of the largescale atmospheric circulation.

a DJF, EXP1-CONT

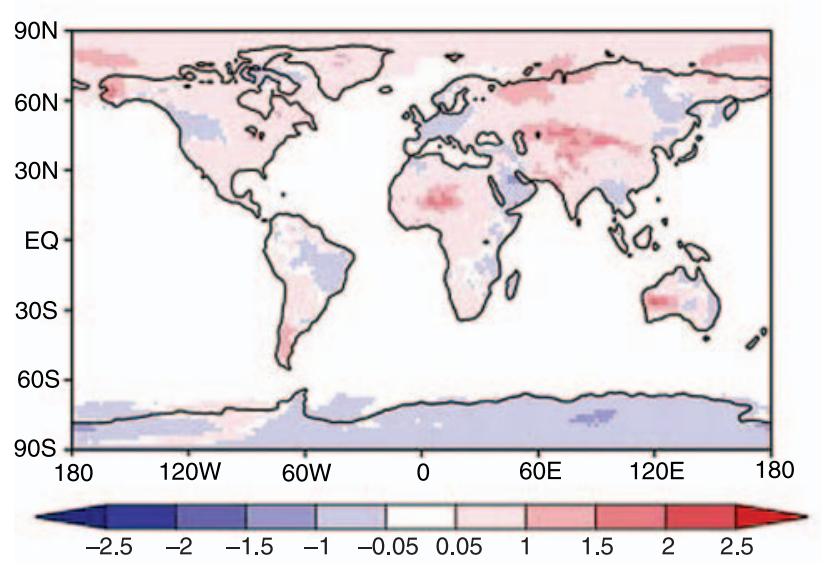

c DJF, EXP2-EXP1

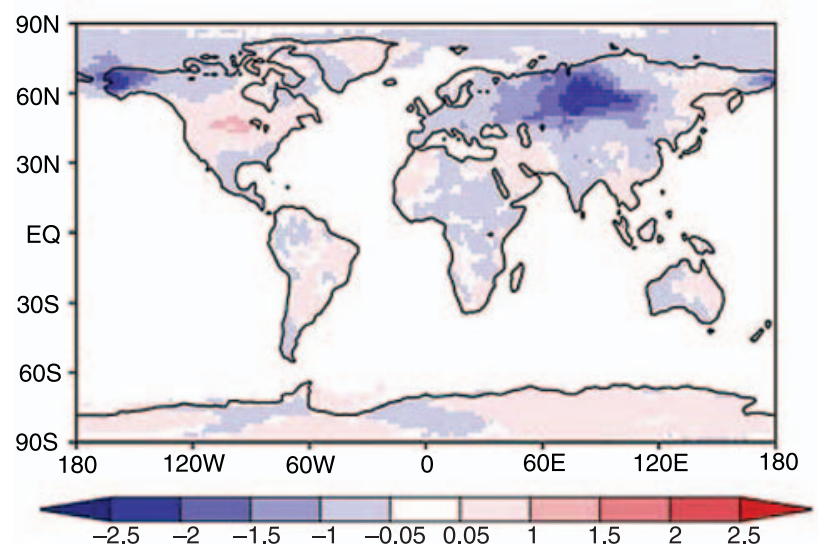

\subsubsection{Surface temperature}

The simulated surface temperature of the climate model is the temperature of the most upper soil layer at $3.25 \mathrm{~cm}$ below the earth's surface. The higher net solar radiation input to the land surface caused by the lower albedo mean of EXP1 compared to the control run CONT leads to higher surface temperatures up to $2 \mathrm{~K}$ in some regions in central Asia, Australia and the western part of northern America especially during the summer season, respectively (Fig. 5a and b). Seasonal albedo variability exhibits no significant influence on surface temperatures during JJA (Fig. 5d), but during DJF (Fig. 5c), an interesting effect occurs over central Siberia and in north-west Alaska. Here, the surface temperatures decrease by more than $2 \mathrm{~K}$ over a large area. The significance of the temperature change was calculated with a one-sided $t$-test. The tempera-

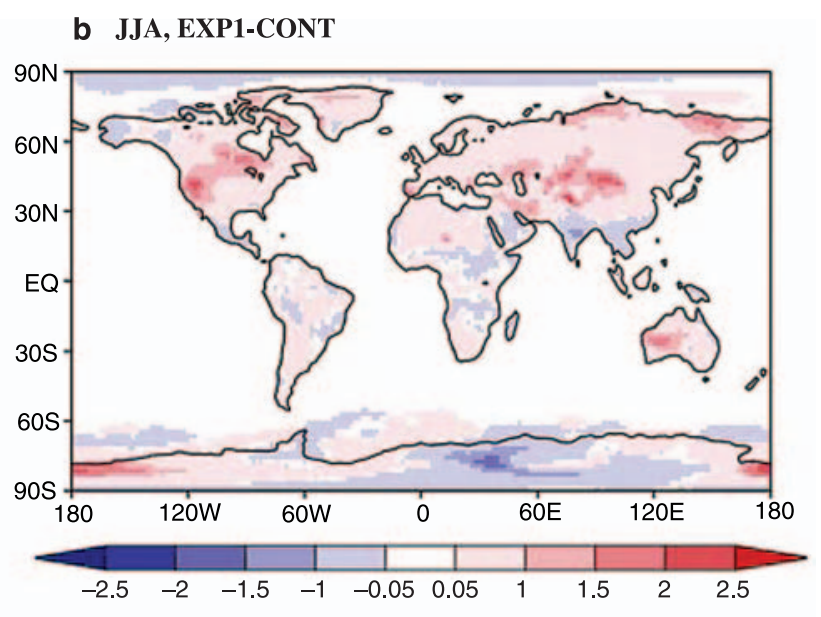

d JJA, EXP2-EXP1

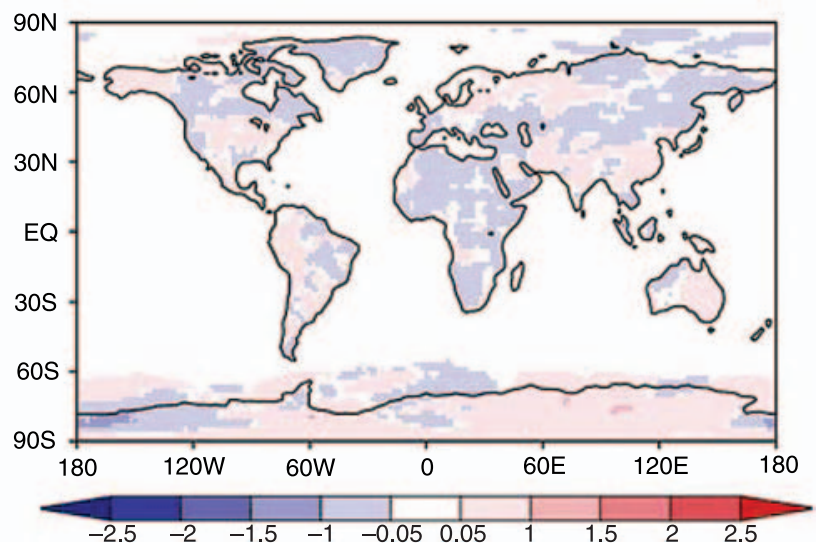

Fig. 5. Seasonal differences of surface temperature $[\mathrm{K}]$ due to the new annual mean background albedo EXP1-CONT (a, b) and due to temporal varying background surface albedo EXP2-EXP1 (c, d) 1979-1999 
a DJF, EXP1-CONT

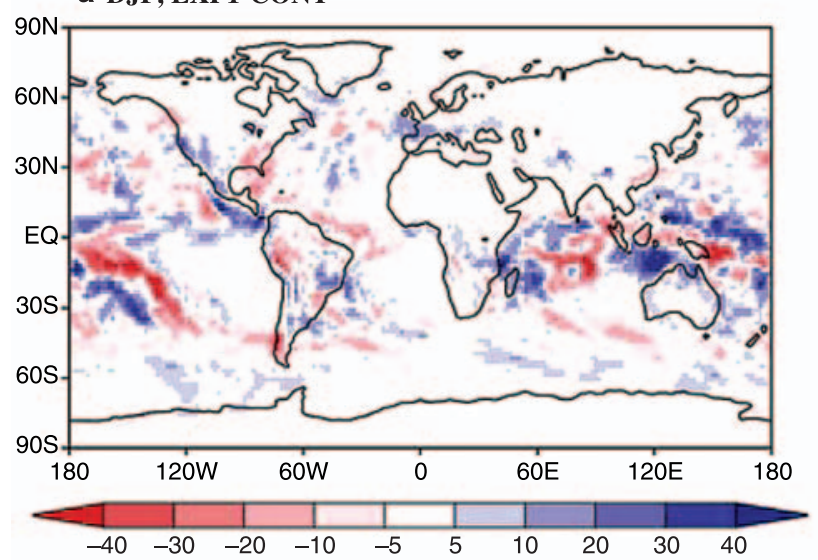

C DJF, EXP2-EXP1

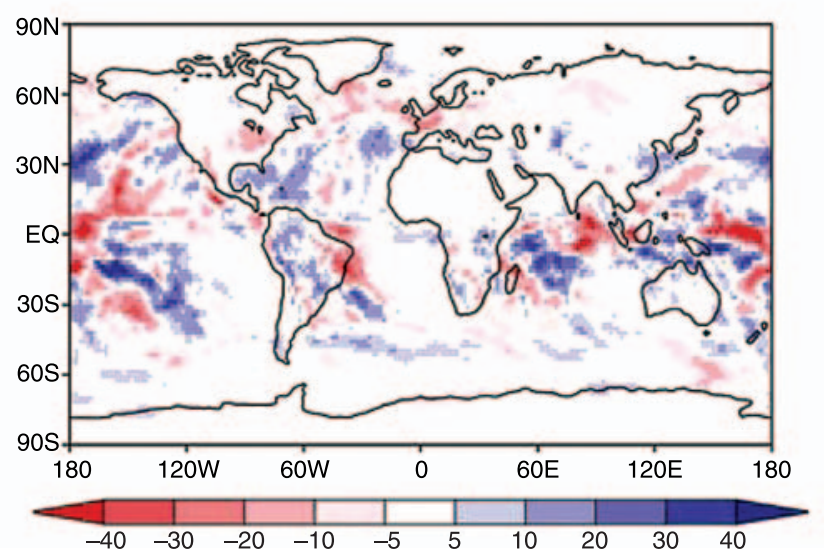

b JJA, EXP1-CONT

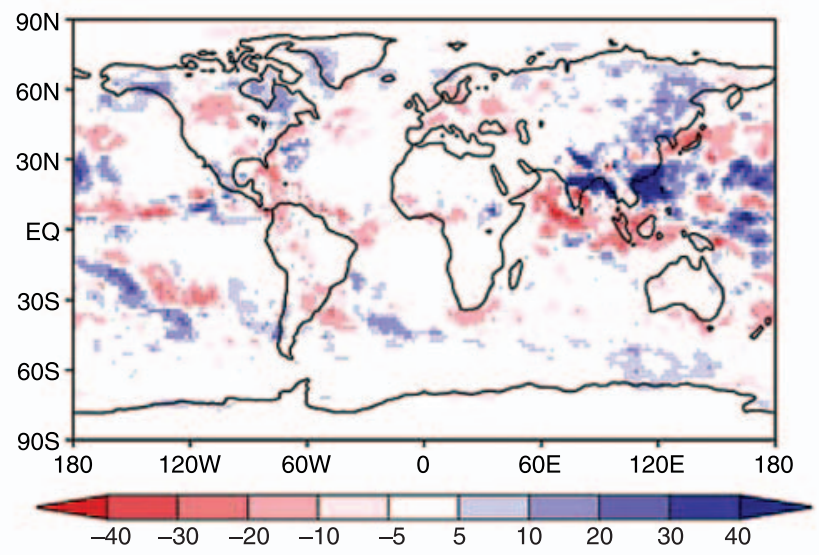

d JJA, EXP2-EXP1

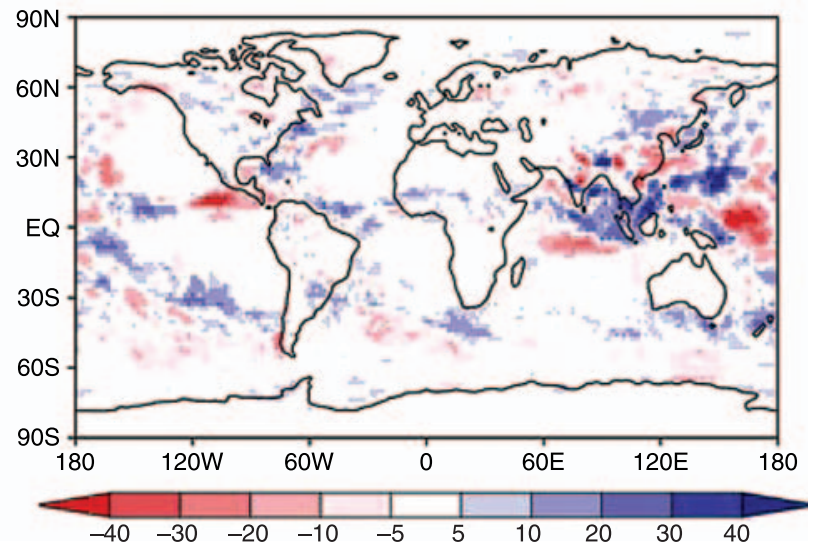

Fig. 6. Seasonal differences of precipitation $[\mathrm{mm} / \mathrm{month}]$ due to the new annual mean background albedo EXP1-CONT (a, b) and due to temporal varying background surface albedo EXP2-EXP1 (c, d) 1979-1999

ture decrease over Siberia is significant at the 95\% confidence level. This means, that the temperature effect in this region is not caused by natural, internal model variability but can be referred to as the seasonal albedo variability. In this region the background albedo did not change at all, also snow cover and snow albedo show no differences. The same effect occurs over Alaska, where the surface temperature is also reduced by $2 \mathrm{~K}$. These remote climate impacts of the changed land surface albedo can only be explained by the modification of the planetary-scale atmospheric circulation (compare Sect. 3.2.7).

\subsubsection{Precipitation}

The main changes in precipitation in both experiments occur over the ocean between $30^{\circ} \mathrm{N}$ and $30^{\circ} \mathrm{S}$ (Fig. 6a-d). This remote effect of the new land albedo scheme again indicates a modi- fication of the large-scale atmospheric circulation. Especially during DJF, precipitation over the tropical Ocean is influenced strongly by the new albedo mean (Fig. 6a) and by the seasonal albedo cycle (Fig. 6c). These figures show partly the reverse effects on the precipitation patterns over the Pacific between $120^{\circ} \mathrm{E}$ and $90^{\circ} \mathrm{W}$ (see also Sect. 3.2.4), over the Gulf of Mexico and over the Indian Ocean between $60^{\circ} \mathrm{E}$ and $90^{\circ} \mathrm{E}$. In regions with increased precipitation, in the majority of cases cloud cover is also increased up to $+5 \%$ (not shown) and vice versa. Over land, no significant precipitation changes occur during DJF. A slight decrease in precipitation up to $-30 \mathrm{~mm} / \mathrm{month}$ in western Europe gives an indication of the weakening of the westerlies, which will be discussed with more detail in Sect. 3.2.7.

During JJA the main precipitation changes caused by the new albedo mean occur over the Pacific Ocean between $30^{\circ} \mathrm{N}$ and the Equator, 
and between $100^{\circ} \mathrm{E}$ and $150^{\circ} \mathrm{W}$ (Fig. 6b). Here, precipitation is increased up to $+40 \mathrm{~mm} /$ month with higher cloud cover up to $+5 \%$ (not shown). The precipitation changes in EXP2 compared to EXP1 (Fig. 6d) turned out to be not significant when the relative precipitation differences were analysed. Over land during JJA, the simulated differences in precipitation between EXP1 and CONT show an intensification of the monsoon over northern India, possibly through changes in the Hadley and/or Walker circulation (not analysed in this study).

\subsubsection{Atmospheric circulation}

The seasonal changes in mean sea-level pressure, net surface solar radiation, surface temperature

\section{a Wind speed and vector at $850 \mathrm{hPa}[\mathrm{m} / \mathrm{s}]$ DJF, EXP1}

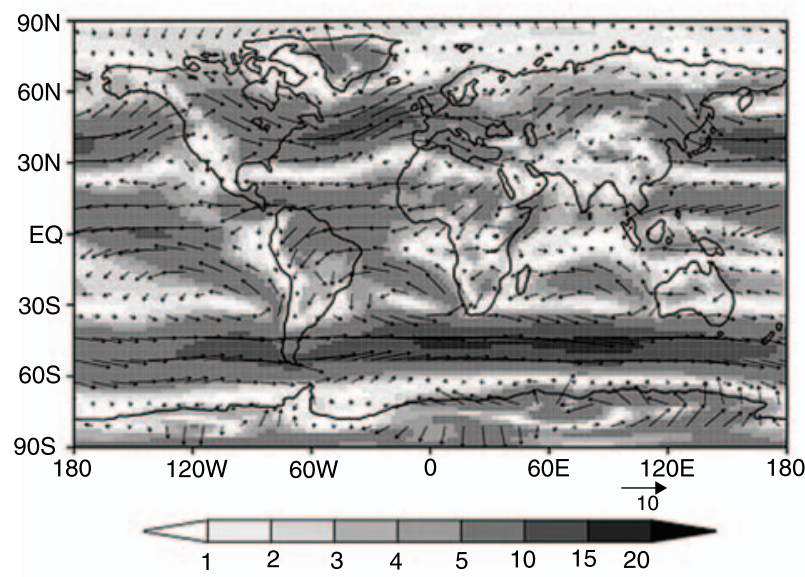

c Vertical velocity at $500 \mathrm{hPa}[\mathrm{hPa} / \mathrm{s}]$ DJF, EXP1

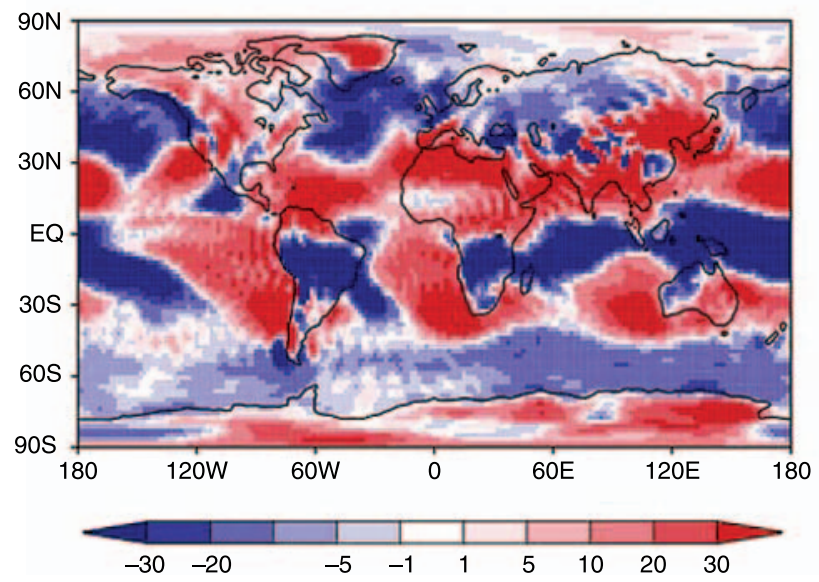

and precipitation caused by the new land surface albedo scheme indicate a modification of the large-scale atmospheric circulation. The effects on the simulated climate are not restricted to regions where land surface albedo is changed, but also occur in remote regions through atmospheric teleconnections. It is not clear which atmospheric processes lead to these remote climate impacts. Several questions are raised: Why is the simulated surface temperature up to $+2 \mathrm{~K}$ higher over a large region in Siberia during the winter season where the seasonal surface albedo is not changed at all? Why does the precipitation pattern change over the tropical ocean whereas surface albedo changes are restricted to land? In order to address these issues, simulated model parameters of the air flow in the troposphere are

\section{b Wind speed and vector at $850 \mathrm{hPa}[\mathrm{m} / \mathrm{s}]$ DJF, EXP2-EXP1}

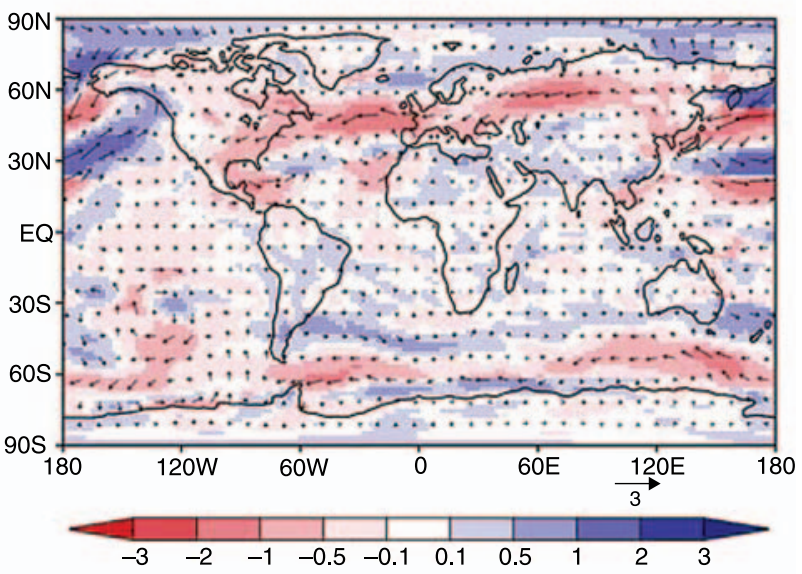

d Vertical velocity at $500 \mathrm{hPa}[\mathrm{hPa} / \mathrm{s}]$ DJF, EXP1-EXP1

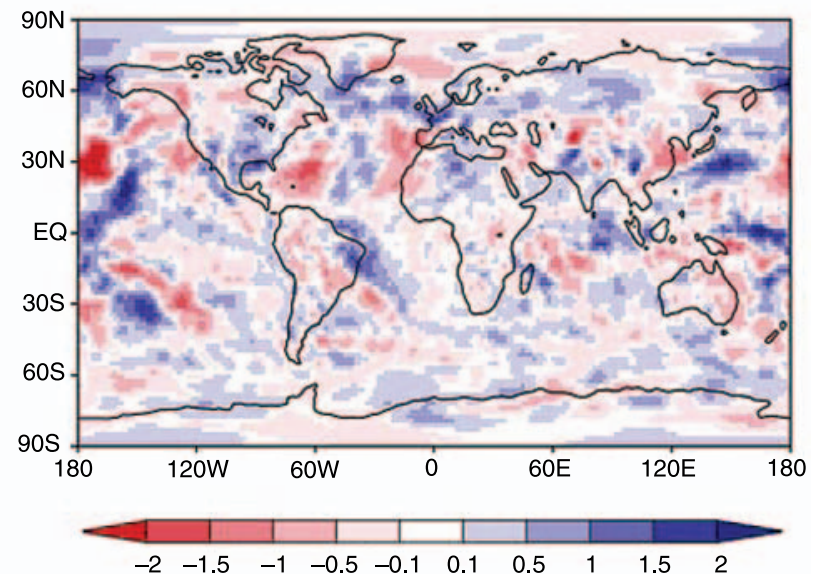

Fig. 7. Seasonal means of wind speed and direction $[\mathrm{m} / \mathrm{s}]$ at $850 \mathrm{hPa}$ (a) and vertical velocity $[\mathrm{hPa} / \mathrm{s}]$ at $500 \mathrm{hPa}(\mathbf{c})$ and seasonal differences due to temporal varying background surface albedo EXP2-EXP1 of wind speed and vector [m/s] at $850 \mathrm{hPa}(\mathbf{b})$ and vertical velocity $[\mathrm{hPa} / \mathrm{s}]$ at $500 \mathrm{hPa}(\mathbf{d})$ during DJF 1979-1999 
analysed. Some selected results of EXP1 and EXP2-EXP1 during DJF are presented in Fig. 7. The global distribution of wind speed and direction at the lower troposphere (Fig. 7a) show zonal patterns in the low and mid-latitudes with strong perturbations caused by the continents and their orography. The differences in horizontal wind speed and wind vector at $850 \mathrm{hPa}$ (Fig. 7b) mainly show zonal wind changes in the mid-latitudes in the Northern and Southern Hemispheres. Especially noticeable is the reduced wind speed up to $-2 \mathrm{~m} / \mathrm{s}$ in the west wind zone over the North Atlantic and western Siberia. Considering the vertical zonal mean of wind speed between $60^{\circ} \mathrm{W}$ and $120^{\circ} \mathrm{E}$ (not shown) this wind change pattern can be seen throughout the whole troposphere with stronger changes in the upper levels between $300 \mathrm{hPa}$ and $200 \mathrm{hPa}$ where the jet stream transports weather systems around the globe. The weakening of the westerlies causes less transport of heat and moisture from the Atlantic Ocean to the Eurasia land masses. This leads to lower winter temperatures over Europe (Fig. 5c) and also to lower precipitation over the continent (Fig. 6c). Further east, the influence of the continental land mass becomes more dominant, which is likely to cause the strong temperature decrease over Siberia. Over the northern Pacific the wind field is also modified but the strong temperature decrease over Alaska seems to be caused by the intensified inflow of Artic cold air into this region.

Which processes lead to the strong modifications of the wind field? Over Northern America and western Europe the total land surface albedo is reduced (Fig. 2c) in EXP2 compared to EXP1 during the Northern Hemisphere winter. The lower surface albedo increases the net surface solar radiation (Fig. 4c). The higher energy input to the earth's surface enhances the turbulent heat fluxes into the atmosphere. Whereas the latent heat flux is unchanged, the sensible heat flux increases over the western part of Northern America. During the winter season with strong vertical temperature gradients this perturbation intensifies and is likely to change the air flow in the whole atmosphere. The global wind field is modified with zonal wind patterns becoming less pronounced. Corresponding to this, the changes in mean sea-level pressure (Fig. 3c) show strong zonal patterns, which can also be seen in the fields of geopotential height in the free atmosphere (not shown). The pressure gradients are partly reduced, as over the North Atlantic between the Icelandic Low and the Azores High. This means a lower North Atlantic Oscillation (NAO) index and a weakening of the westerlies.

During DJF in EXP2 compared to EXP1 the wind patterns between $30^{\circ} \mathrm{N}$ and $30^{\circ} \mathrm{S}$ are hardly changed. But the analysis of the simulation results in the previous sections showed remote climate impacts of the land surface albedo changes in the tropics and especially over the tropical ocean. To examine the vertical air motion, the changes in vertical velocity in the middle troposphere at $500 \mathrm{hPa}$ are presented in Fig. $7 \mathrm{~d}$. To interpret these differences, the vertical velocity of EXP1 is displayed in Fig. 7c. Positive algebraic signs mean sinking air motion and negative signs mean rising air motion. The differences in vertical velocity show the same patterns as the differences in precipitation (Fig. 6c). This is also the case for the changes between EXP1 and CONT (not shown). This means that locations with changes in ascending and descending air motions are consistent with the changes in precipitation, cloud cover and solar radiation (compare also Sect. 3.2.4). In regions where rising air motion is enhanced or sinking air motion is weakened, cloud cover and precipitation are increased and net surface solar radiation is lower. In regions where the rising air motion is weakened or the sinking is enhanced, cloud cover and precipitation is reduced and the net surface solar radiation is higher. But why is the vertical air motion modified over the tropics, far away from the regions where surface albedo is changed? Here, we would like to give a short view on state of the art studies on this question. Tanaka et al. (2005) concluded that the velocity potential at $200 \mathrm{hPa}$ contains information about the overall intensity of the tropical circulation. The changes in velocity potential in our study show partly similar patterns as the precipitation changes over the tropics (not shown). Also the changed streamfunction at $200 \mathrm{hPa}$ (not shown) illustrates clearly the modified patterns indicating largescale modifications of the atmospheric circulation. These planetary-scale perturbations in the velocity potential and streamfunction fields may provide the basis for a possible teleconnection 
mechanism between the Northern Hemisphere and the Southern Hemisphere (Burke et al. 2000). Chase et al. (2000) state that these planetaryscale changes impact divergence, and some of the remote climate impacts of land surface changes may result from the vorticity transport set up by this perturbed large-scale divergent field. Vorticity budget studies have shown that the transport of vorticity by the divergent field is an effective transport mechanism, especially for tropical - extratropical teleconnections (Sardeshmukh and Hoskins 1987).

\section{Regional simulations with REMO}

\subsection{Model simulations}

As for the global simulations with ECHAM5 three regional model simulations were performed to study the sensitivity of the simulated regional climate to the background surface albedo vari-

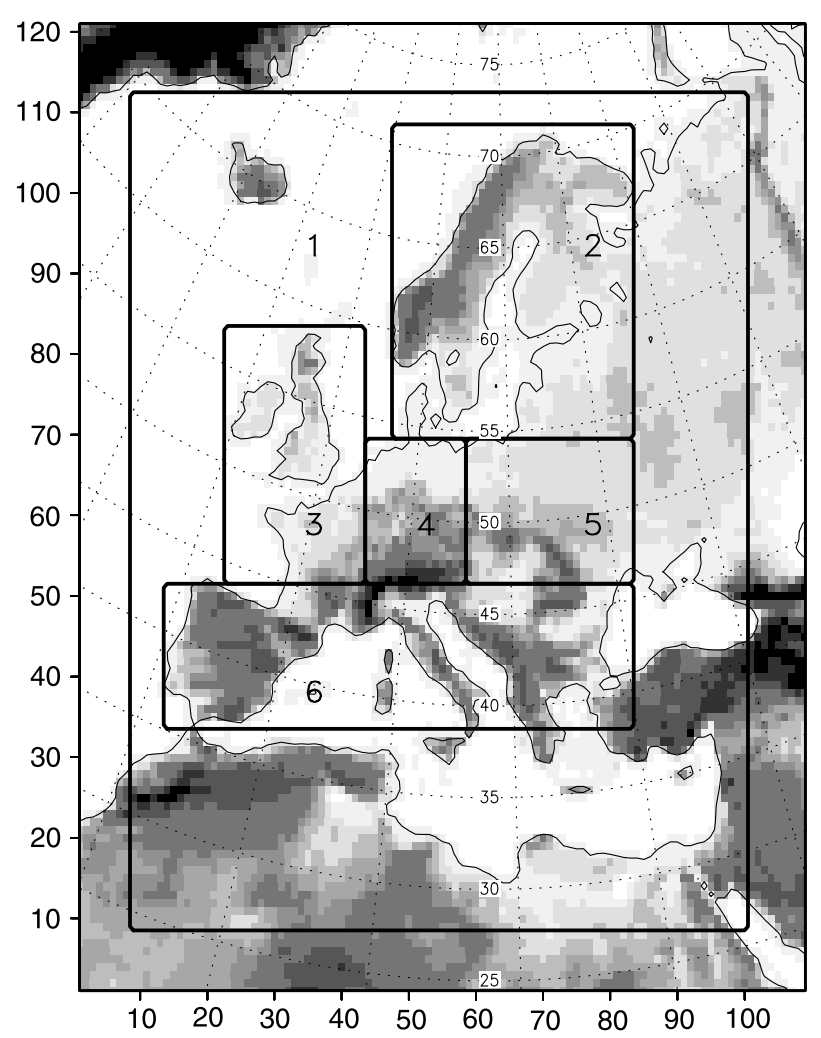

Fig. 8. REMO model orography $[\mathrm{m}]$ at 0.44 degree horizontal resolution with European sub-domains: 1 model domain area without the 8 boundary grid boxes, 2 northern Europe, 3 western Europe, 4 central Europe, 5 eastern Europe, 6 southern Europe ability. The simulations are done at 0.44 horizontal resolution with 31 vertical levels for the 15-year time period from 1979 to 1993 driven by lateral boundary conditions and sea surface temperatures from the European Centre for MediumRange Weather Forecasts (ECMWF) Reanalysis Project (ERA40: Uppala et al. 2005): 1. control simulation with the currently used time-invariant surface background albedo $=$ CONT, 2. experiment with the new mean time-invariant surface background albedo field $=\mathbf{E X P 1}$, 3. experiment with the time-varying surface background albedo as a function of the leaf area index $=\mathbf{E X P 2}$. The model domain focusing on Europe is shown in Fig. 8. It presents the model orography by European sub-region, which are used for some evaluations. The model results are evaluated for the 15 -year time period from 1979 to 1993 . The regional model simulations only cover this 15 year time period performed in the context of further sensitivity studies. For the comparison between the regional and global simulation results in Sect. 5, the same time period is extracted from the global results.

\subsection{Results}

\subsubsection{Background albedo}

For the regional model domain the horizontal differences between the surface background albedos in the three simulations (EXP1-CONT and EXP2-EXP1) in Fig. 9 show the same patterns as for the global experiments (compare Sect. 3.2.1), but with more detail. Figure 9a presents the regional horizontal distribution of the new annual mean background albedo of EXP1, and Fig. 9b the difference between the new and old annual mean background albedo EXP1CONT. The new annual background albedo means, derived from MODIS data, show mainly lower values up to differences of -0.05 over Europe. The seasonal albedo variability leads to higher background albedo values during the summer season (Fig. 9d) and lower values during the winter season (Fig. 9c) compared to the new annual mean. In Europe the soils are mainly darker than vegetation. The greening up of plants during the growing season leads to higher surface albedos, whereas during the dormancy season the darker background soil becomes more visible. 
a EXP1

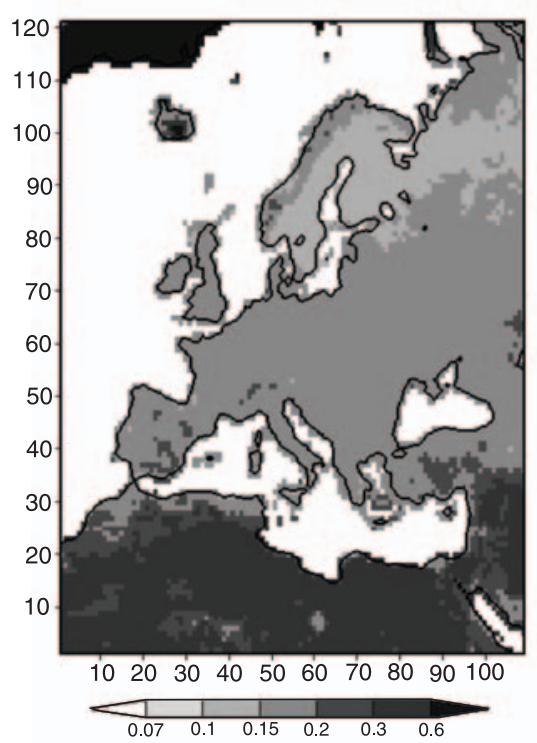

C DJF, EXP2-EXP1

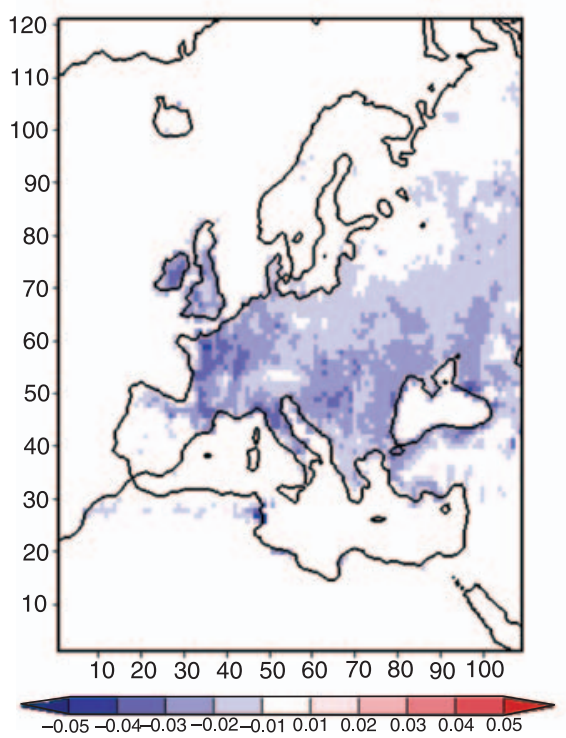

\section{b EXP1-CONT}

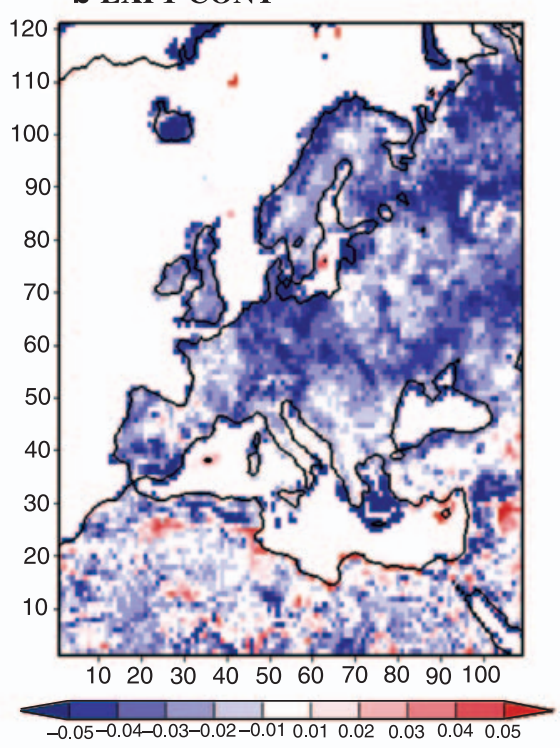

d JJA, EXP2-EXP1

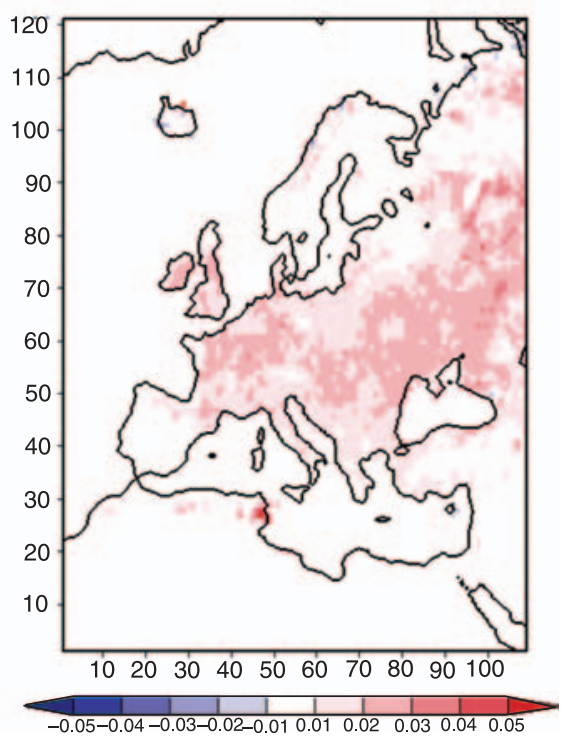

Fig. 9. New annual mean background albedo of EXP1 (a) compared to the old annual mean EXP1-CONT (b) and seasonal differences for DJF (c) and JJA (d) of temporal varying background albedo compared to the new annual mean EXP2-EXP 1979-1993
Together, the representation of the seasonal surface albedo variations in the regional climate model is clearly improved especially for Europe (Rechid et al. 2007).

\subsubsection{Total surface albedo}

The differences of the simulated total surface albedo caused by the new background albedo parameterisation show the same patterns as for the background albedo itself, except for the northern part of Europe, where the background is covered by snow during the winter season without changes (not shown).

\subsubsection{Mean sea-level pressure}

In contrast to the global simulation results, the regional experiments show no significant changes in mean sea-level pressure (not shown) and the circulation patterns are not modified. The external forcing prescribes the large-scale boundary conditions; only local effects of the new albedo parameterisation are expected.

\subsubsection{Net surface solar radiation}

During the winter season the new albedo parameterisation has almost no effect on the simulated net surface solar radiation (not shown). Only 
a JJA, EXP1-EXP1

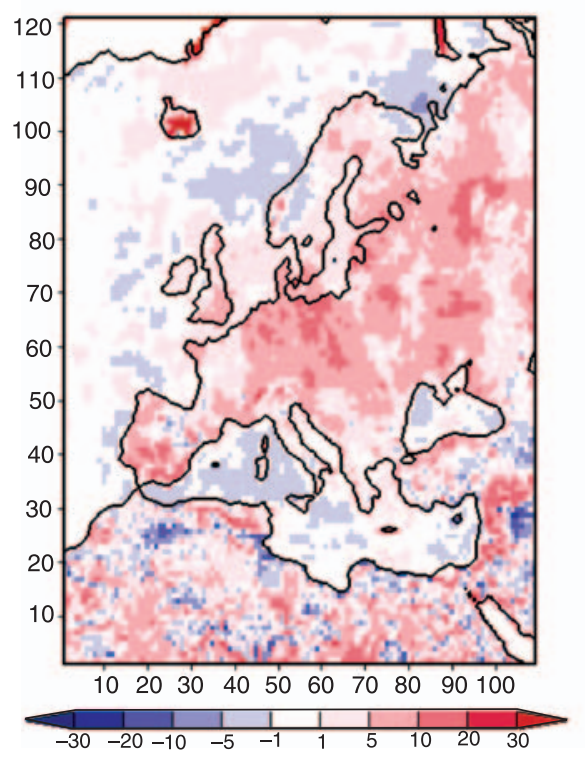

b JJA, EXP2-EXP1

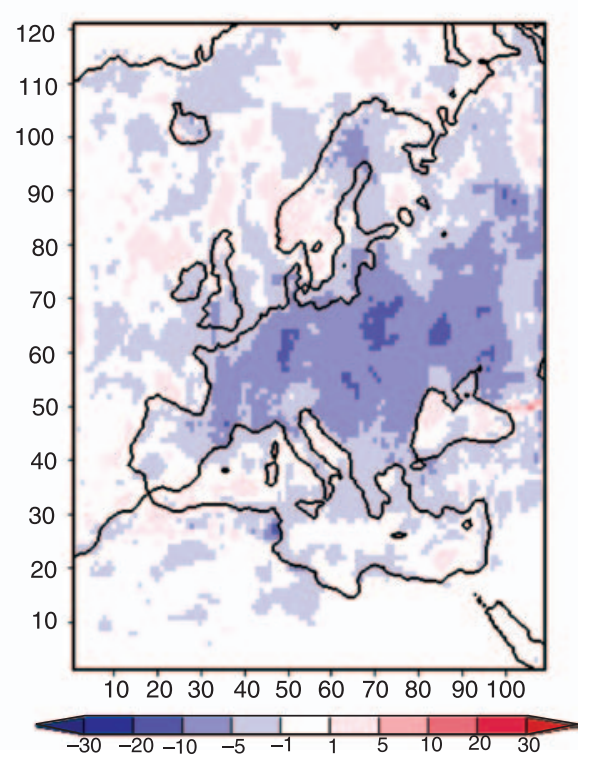

Fig. 10. Differences of net surface solar radiation $\left[\mathrm{W} / \mathrm{m}^{2}\right]$ due to the new annual mean background albedo EXP1-CONT (a) and due to temporal varying background surface albedo EXP2-EXP1 (b) for JJA 1979-1993 in southern Europe there is a slight increase in the solar radiation input to the earth's surface. However, the total solar radiation input during DJF is relatively low due to high cloud cover and shorter length of the days, so that radiation fluxes at the surface are quite low compared to the conditions during the summer season. In JJA the lower mean background albedo leads to higher solar radiation input to the surface, especially on the Iberian Peninsula and Iceland (Fig. 10a). Over Iceland the new albedo scheme replaced the old albedo mean of constant ice cover with more realistic lower albedo values during the summer season. In Fig. 10b the higher background albedo during summer caused by the seasonal variability of the albedo cycle translates directly into lower net surface solar radiation up to $-30 \mathrm{Wm}^{-2}$. In many regions the radiation effects of the new albedo mean and the seasonal varying albedo compared to the control run compensate each other.

\subsubsection{Surface temperature}

The seasonal background albedo cycle has no effect on surface temperature during the winter season (not shown) as it caused no changes in the

\section{a JJA, EXP1-CONT}

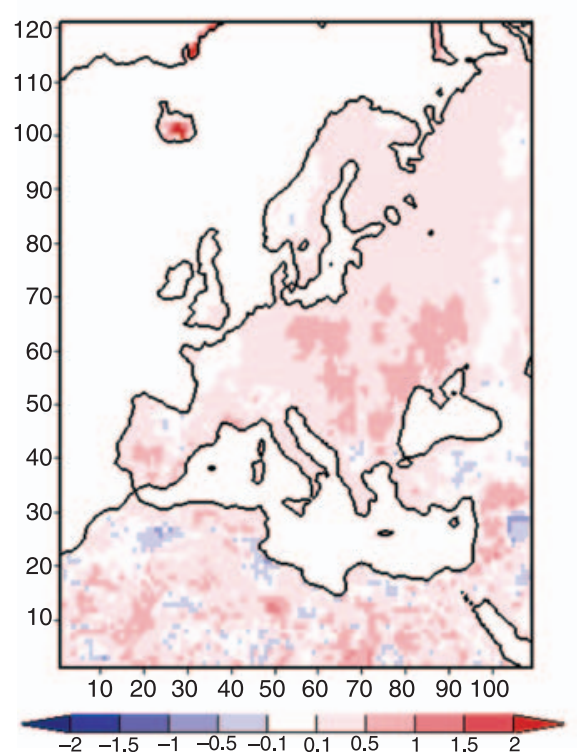

b JJA, EXP2-EXP1

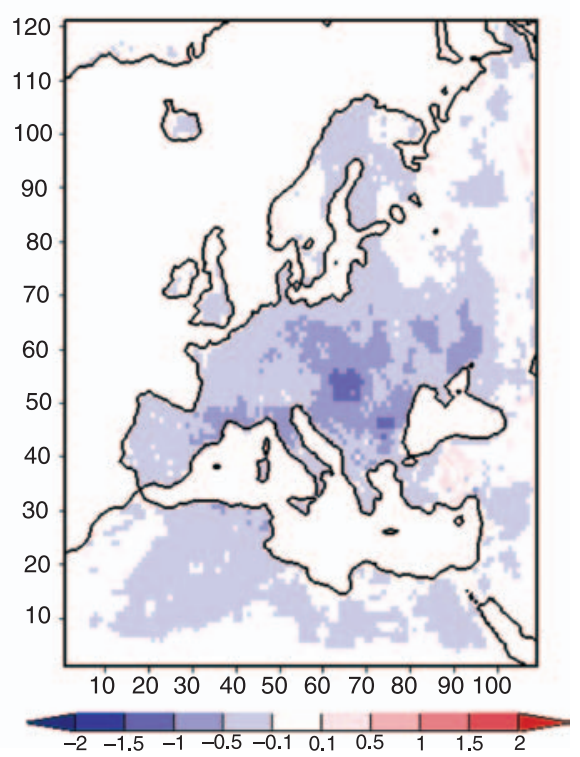

Fig. 11. Differences of surface temperature $[\mathrm{K}]$ due to the new annual mean background albedo EXP1-CONT (a) and due to temporal varying background surface albedo EXP2-EXP1 (b) for JJA 1979-1993 
a JJA, EXP1-EXP1

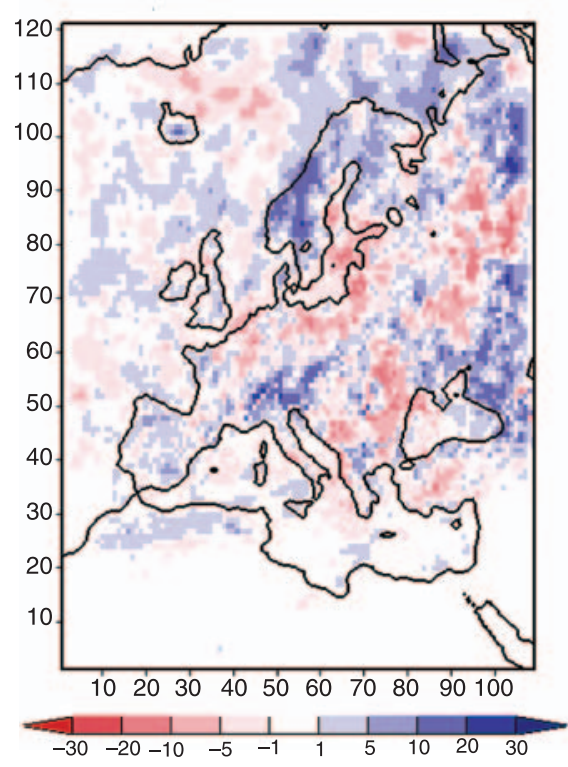

b JJA, EXP2-EXP1

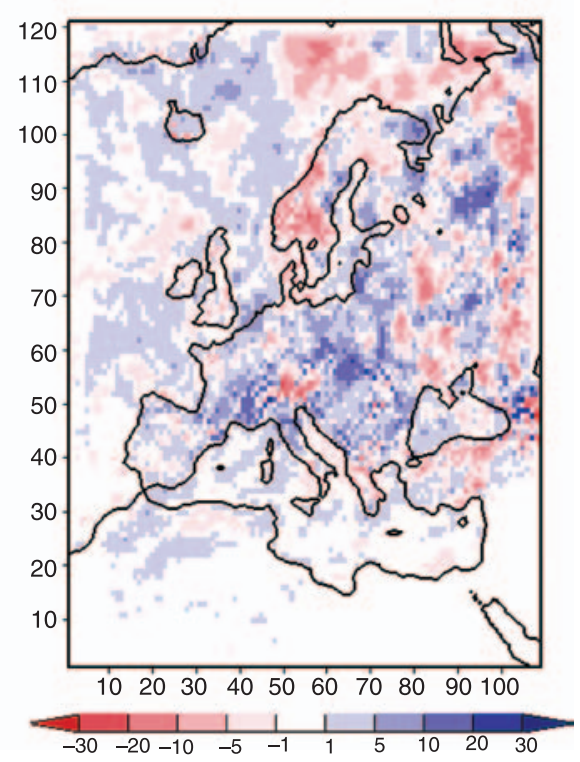

Fig. 12. Differences of precipitation $[\mathrm{mm} / \mathrm{month}]$ due to the new annual mean background albedo EXP1-CONT (a) and due to temporal varying background surface albedo EXP2-EXP1 (b) for JJA 1979-1993 net surface solar radiation (compare Sect. 4.2.4). In addition, the influence of the new albedo mean is negligible as snow cover dominates the surface properties during DJF. During the summer season, the higher solar radiation input to the surface due to the lower mean background albedo (EXP1-CONT) leads to higher temperatures by up to $+1.5 \mathrm{~K}$ in eastern Europe during JJA (Fig. 11a). For the comparison of EXP2-EXP1 in Fig. 11b the lower solar radiation input to the land surface due to higher background albedo values in JJA causes lower surface temperatures by up to $-1.5 \mathrm{~K}$. Together, as for the net surface radiation, the effects of the new albedo mean and the seasonal varying albedo on surface temperatures compensate each other in most regions.

\subsubsection{Precipitation}

As for the net surface solar radiation and the surface temperatures, the seasonal background albedo cycle and the new albedo mean have almost no effect on precipitation during the winter season (not shown). During JJA stronger effects on precipitation occur (Fig. 12a and b). In many regions the precipitation changes do not show systematic patterns and probably result from the high sensitivity of the precipitation parameter to model experiments. Systematic differences seem to occur over the Alps and over south-west Scandinavia with higher precipitation up to $+30 \mathrm{~mm} / \mathrm{month}$ in EXP1 compared to CONT and lower precipitation up to $-20 \mathrm{~mm} /$ month in EXP2 compared to EXP1. However, these absolute differences are not significant compared to the high total amount of precipitation in both regions. They might indicate some smaller changes in the circulation patterns within the regional model domain, which is much less pronounced than in the global model experiments.

\section{Comparison of the global and regional sensitivity studies}

\subsection{Temperature}

In the following, the results from the global and the regional sensitivity studies are compared. For this purpose the results from the GCM are prepared for the same region and time period as for the RCM results. In Fig. 13 the seasonal differences of $2 \mathrm{~m}$ temperatures caused by the temporal varying background surface albedo (EXP2EXP1) are displayed for the global and regional experiments over Europe. The global and regional studies show different results. Whereas in REMO, during DJF, no significant changes occur, in the global experiment temperature decreases especially in north-east of Europe by up to $-2 \mathrm{~K}$. For the summer season, the global results show a slight increase in temperature by up to $+1 \mathrm{~K}$ over central and eastern Europe. In contrast, in the regional simulation the temperature 
ECHAM: DJF, EXP2-EXP1

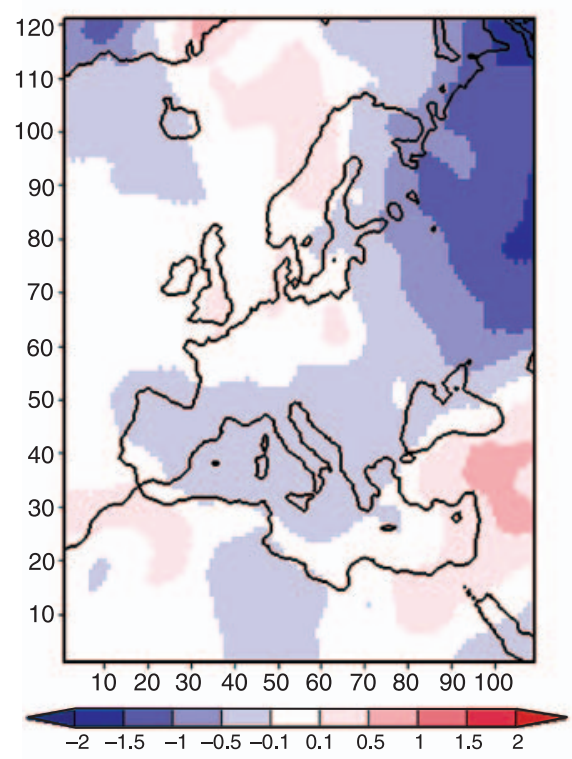

ЕСНАM: JJA, EXP2-EXP1

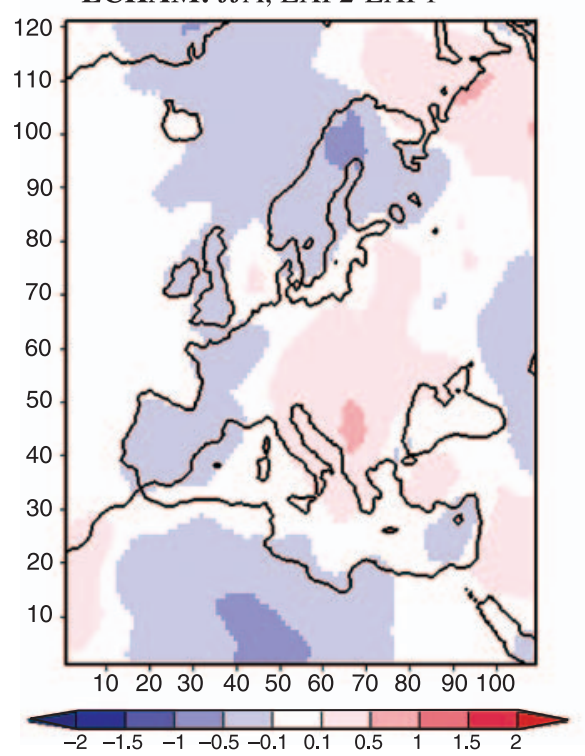

REMO: DJF, EXP2-EXP1

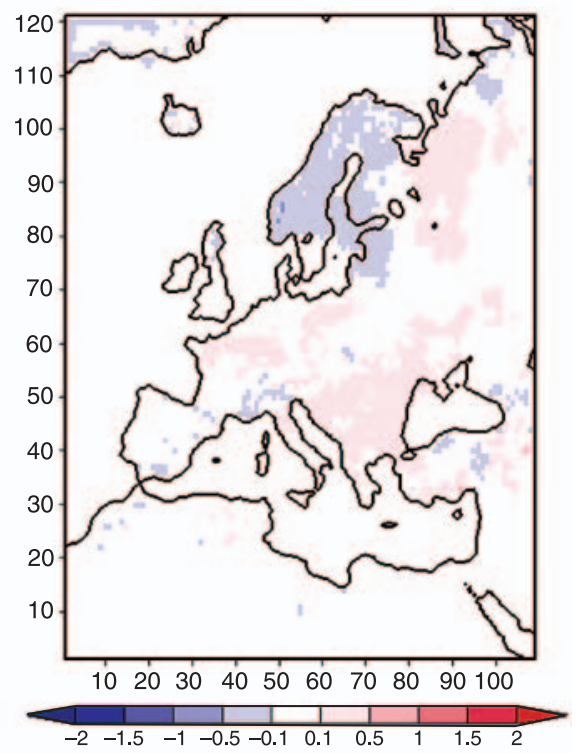

REMO: JJA, EXP2-EXP1

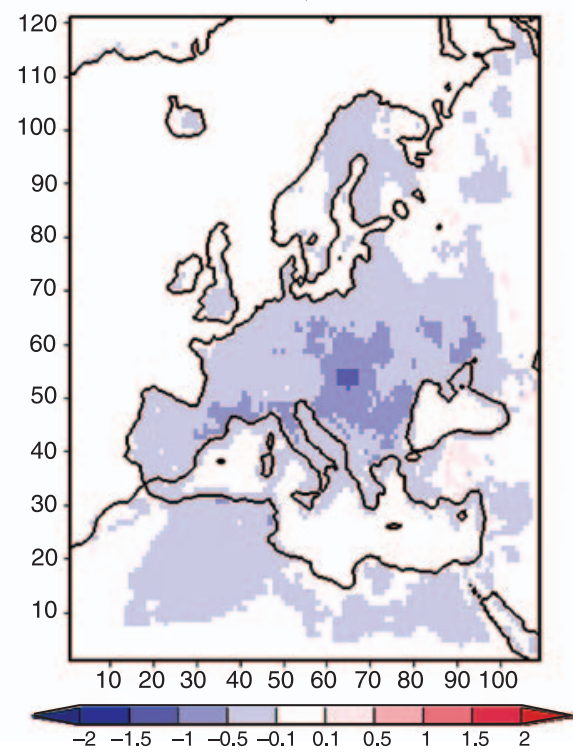

Fig. 13. Seasonal differences of $2 \mathrm{~m}$-temperature $[\mathrm{K}]$ due to temporal varying background surface albedo (EXP2-EXP1) 19791993 in the global and regional experiments decreases in this region during JJA by up to $-1.5 \mathrm{~K}$. In the regional model, this is a clear local response in temperature to the seasonal background albedo variability with higher albedo during JJA and lower solar radiation input to the surface compared to the annual constant mean. In the global simulation, the local processes are superposed by the changed large-scale conditions. In Fig. 14 the differences in the mean annual cycles of $2 \mathrm{~m}$ temperatures between EXP2EXP1, EXP2-CONT and EXP1-CONT are compared for the global (dashed lines) and the regional simulations (solid lines) for selected sub- areas. With the exception of eastern Europe, the global results show higher sensitivity to the changed albedo parameterisation.

\subsection{Precipitation}

In Fig. 15 the seasonal differences in precipitation caused by the temporal varying background surface albedo (EXP2-EXP1) are presented for the global and regional experiments over Europe. Again, the global and regional studies show different results. Whereas in REMO, during DJF, no remarkable changes occur, in 
2m Temperature [K] 1979-1993

Northern Europe

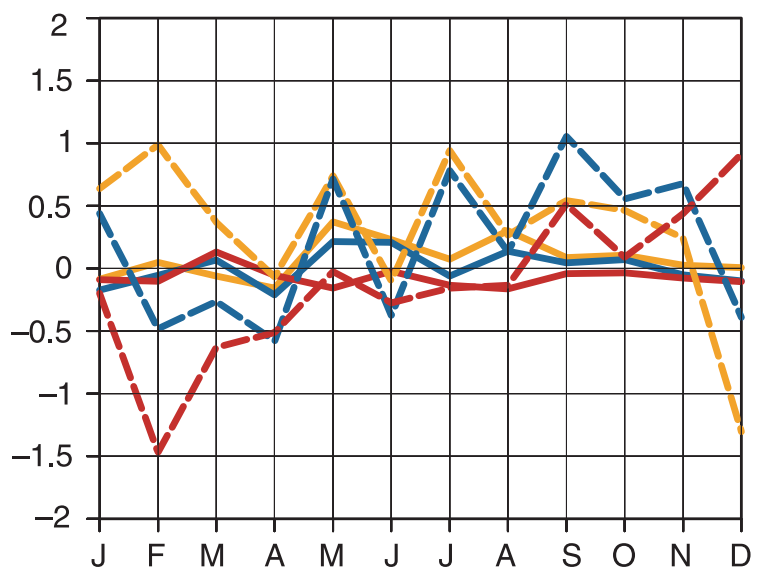

Central Europe

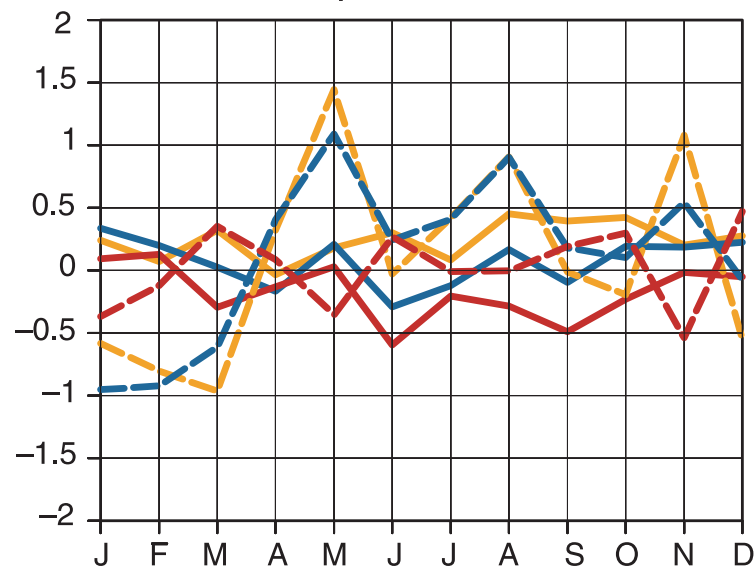

Southern Europe

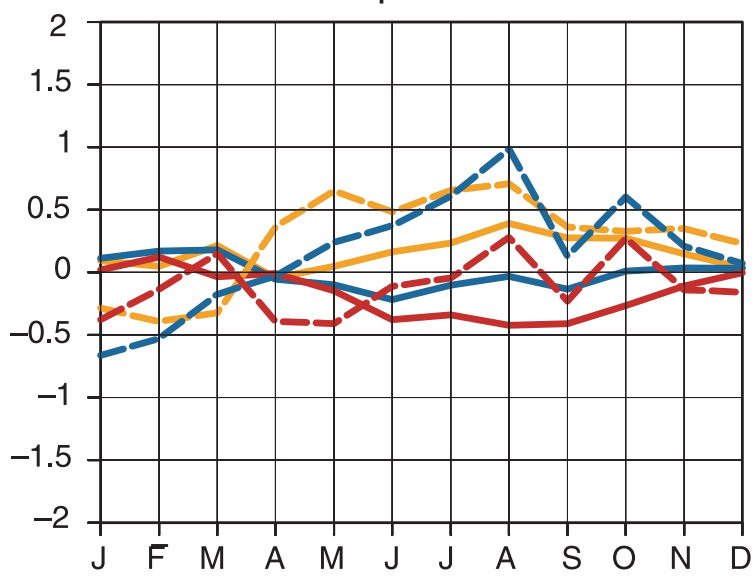

Western Europe

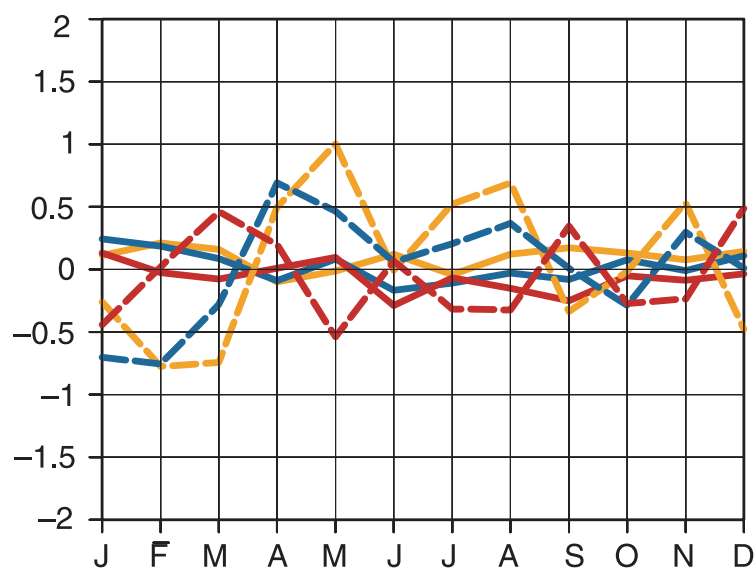

Eastern Europe

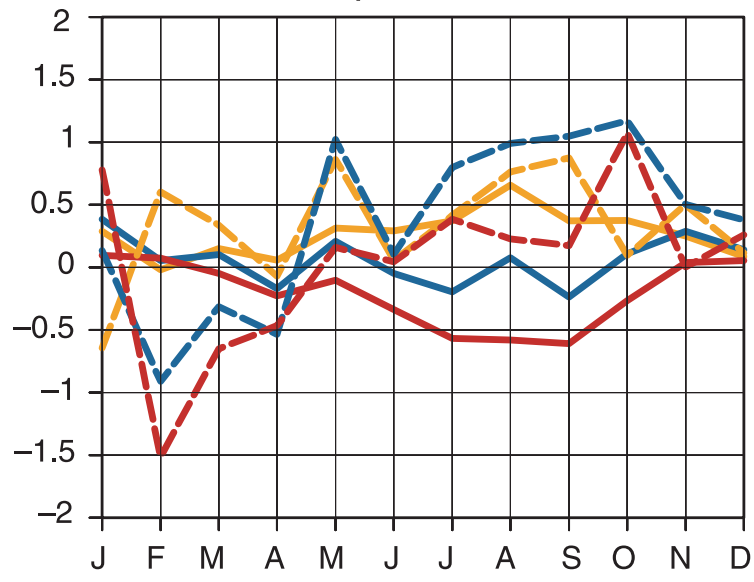

Model domain

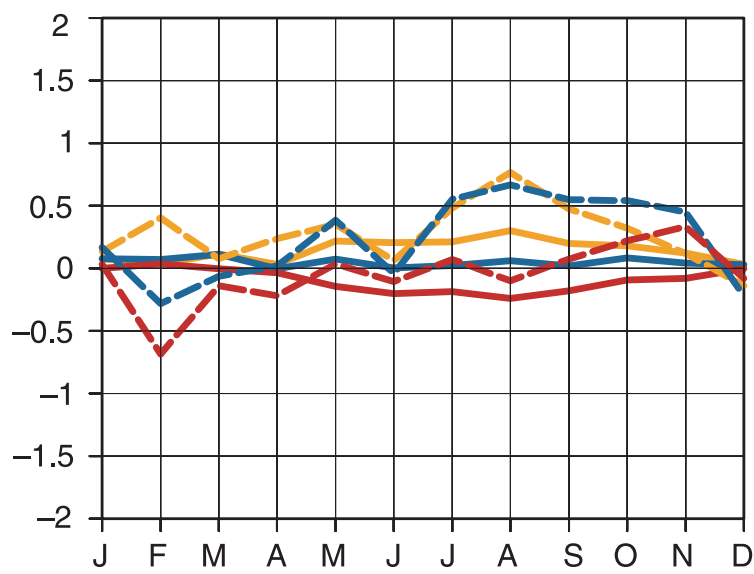
EXP1-CONT

EXP2-CONT

EXP2-EXP1

Fig. 14. Annual cycles of $2 \mathrm{~m}$ temperature differences [K] 1979-1993 between EXP1-CONT, EXP2-CONT and EXP2-EXP1 for the global simulations (dashed lines) and for the regional results (solid lines) 
ECHAM: DJF, EXP2-EXP1

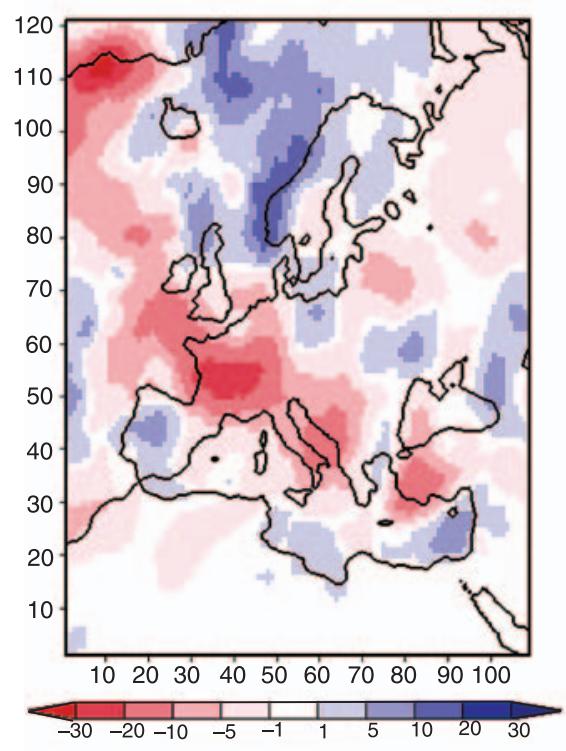

ECHAM: JJA, EXP2-EXP1

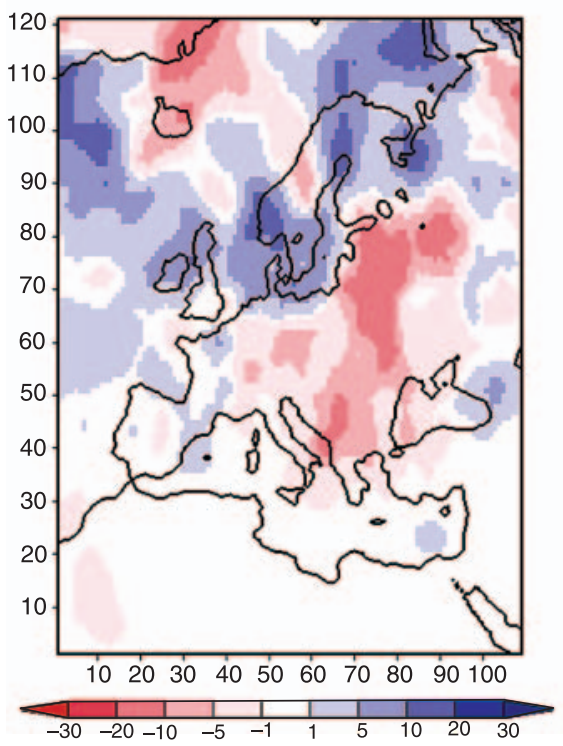

REMO: DJF, EXP2-EXP1

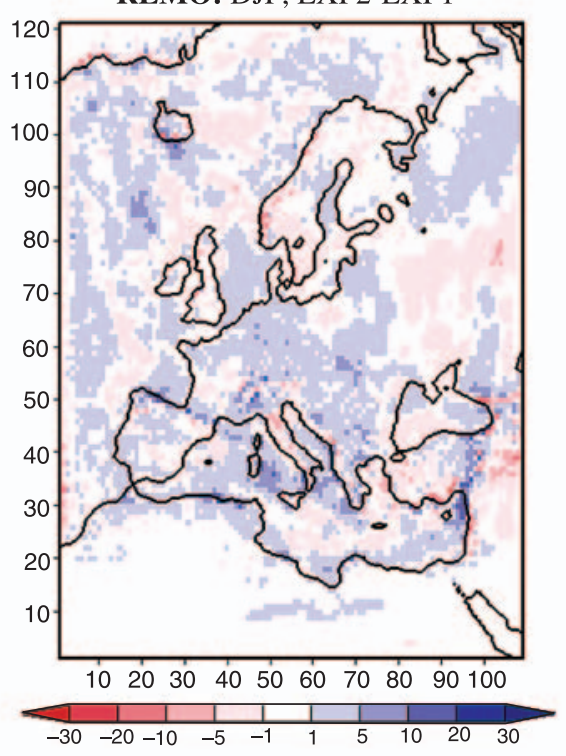

REMO: JJA, EXP2-EXP1

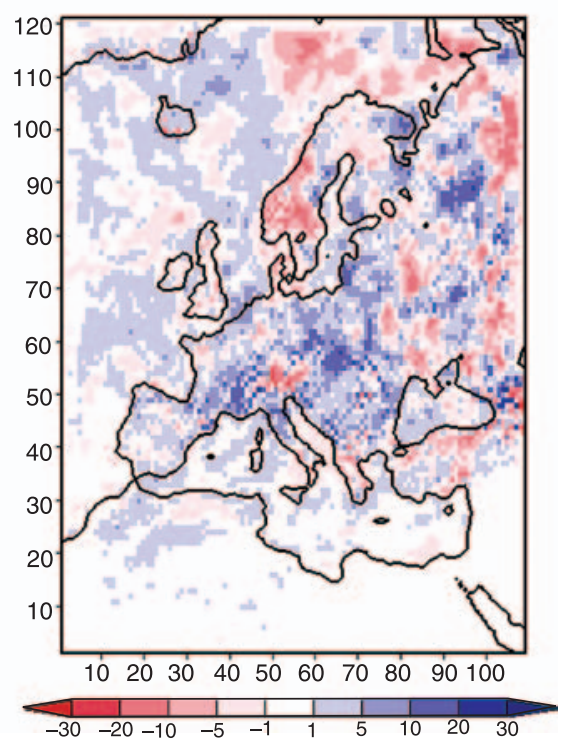

Fig. 15. Seasonal differences of precipitation $[\mathrm{mm} / \mathrm{month}]$ due to temporal varying background surface albedo (EXP2-EXP1) 1979-1993 in the global and regional experiments the global experiment the precipitation decreases in western and central Europe by up to $-30 \mathrm{~mm} /$ month. This precipitation decrease is significant on the $95 \%$ level estimated by the one-sided $t$ test. The lower precipitation values result possibly from weakened westerlies caused by the changed pressure regime with lower NAO index as discussed in Sect. 3.2.3. In contrast to the global simulation, where the large-scale conditions are changed by the new albedo parameterisation, in the regional simulations the circulation patterns within the model domain are not influenced. Here, the external forcing via the lateral boundaries of the regional model domain suppress changes in the large-scale circulation that might occur without the external forcing. In JJA, the global and regional patterns also look different. Whereas in the global study the summer precipitation slightly decreases by up to $-20 \mathrm{~mm} / \mathrm{month}$ over central and eastern Europe, in the regional simulation the precipitation slightly increases by up to $20 \mathrm{~mm} / \mathrm{month}$ in this area, except for the eastern Alpine region. Also, for southern Scandinavia, the global and regional simulations show contrasting results with increased values in ECHAM5 and decreased values in REMO. Together, due to the higher resolution of the regional simulations more horizontal de- 
Precipitation [mm/month] 1979-1993
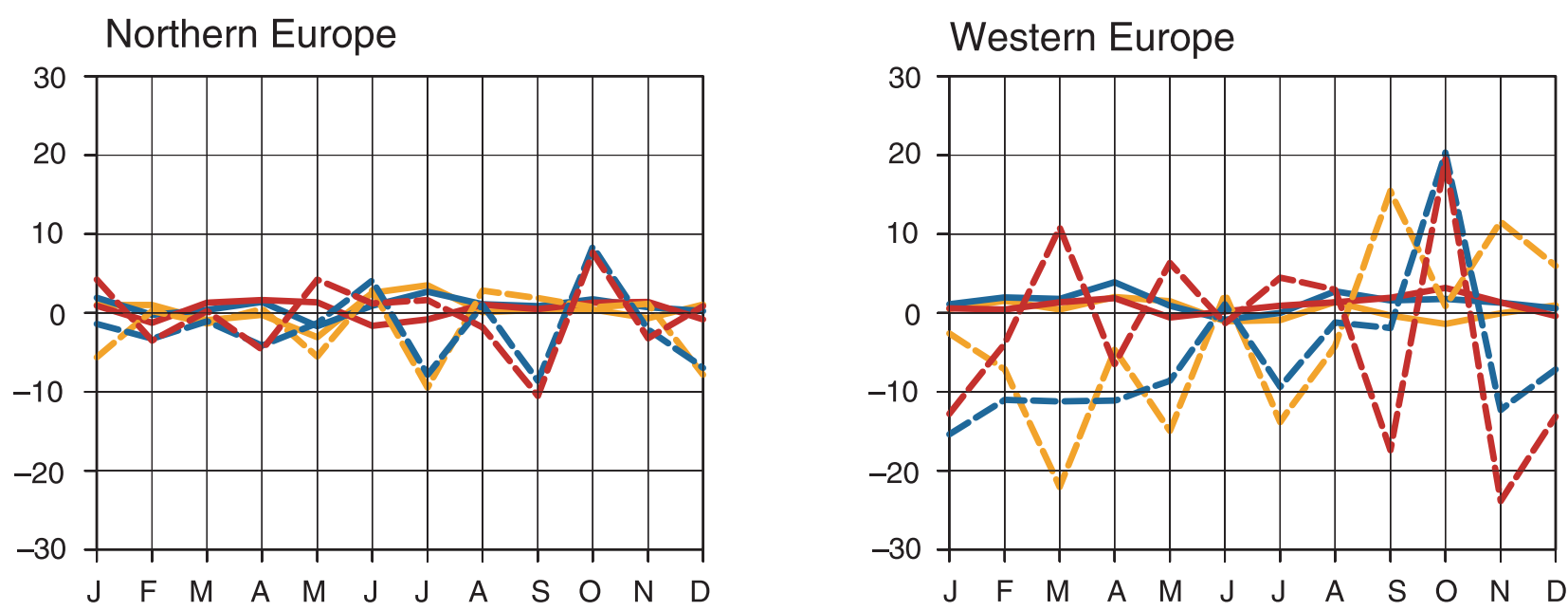

\section{Central Europe}

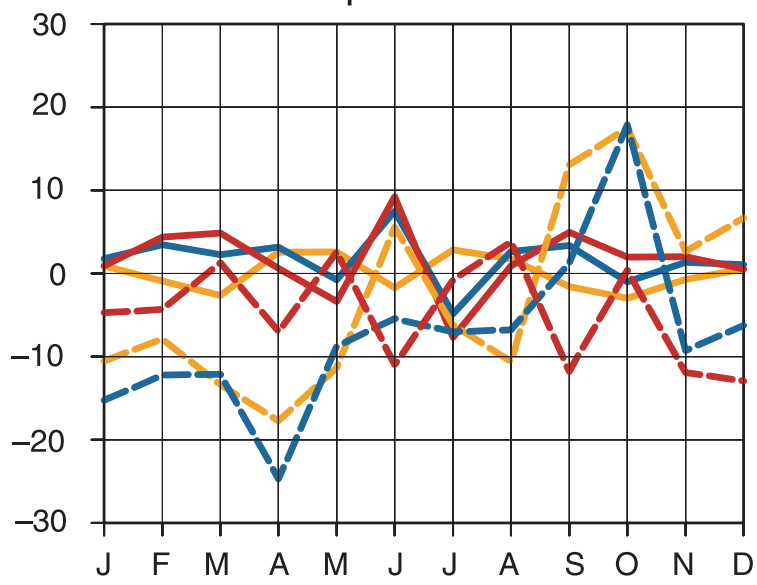

Southern Europe

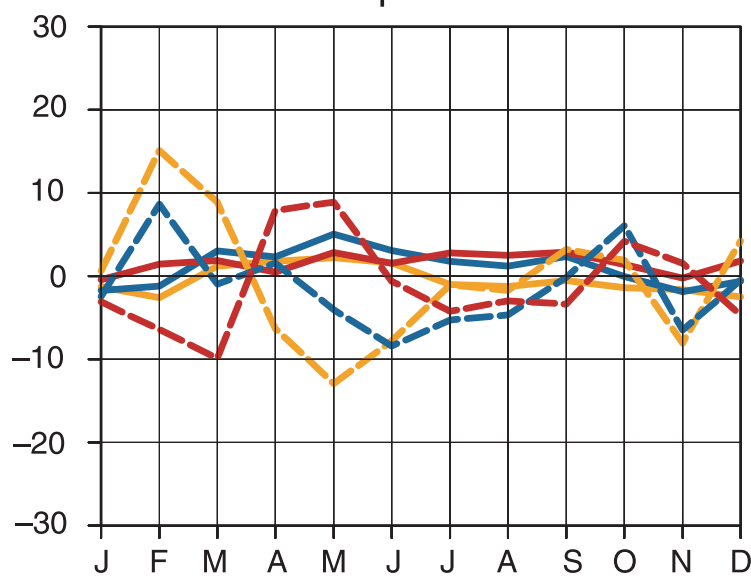

Eastern Europe

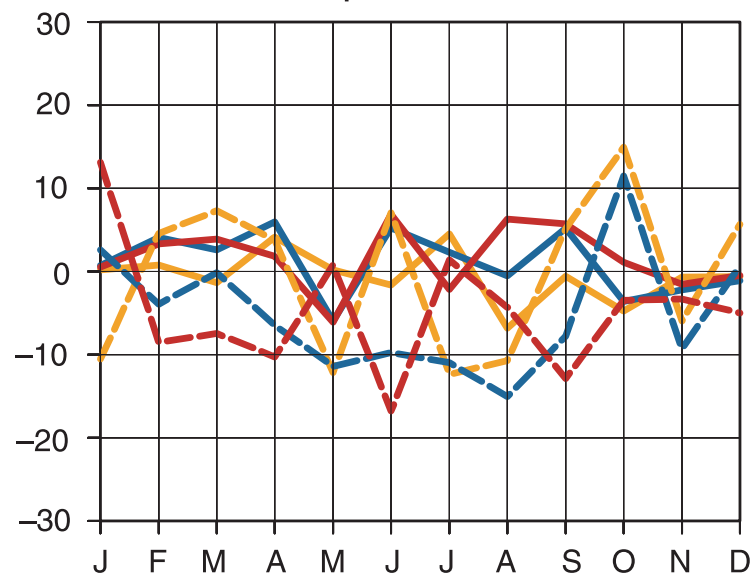

Model domain

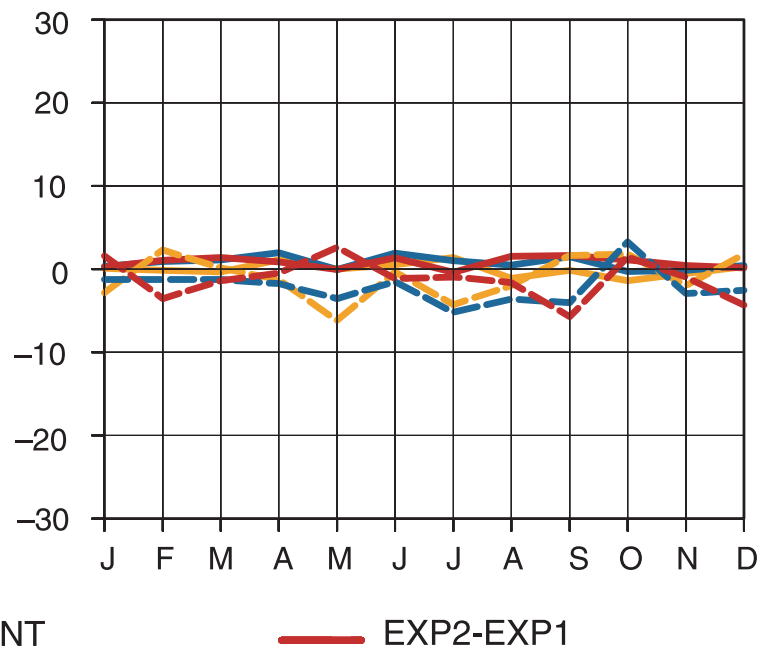

Fig. 16. Annual cycles of precipitation differences [mm/month] 1979-1993 between EXP1-CONT, EXP2-CONT and EXP2EXP1 for the global simulations (dashed lines) and for the regional results (solid lines) 
2m Temperature [K] 1979-1993
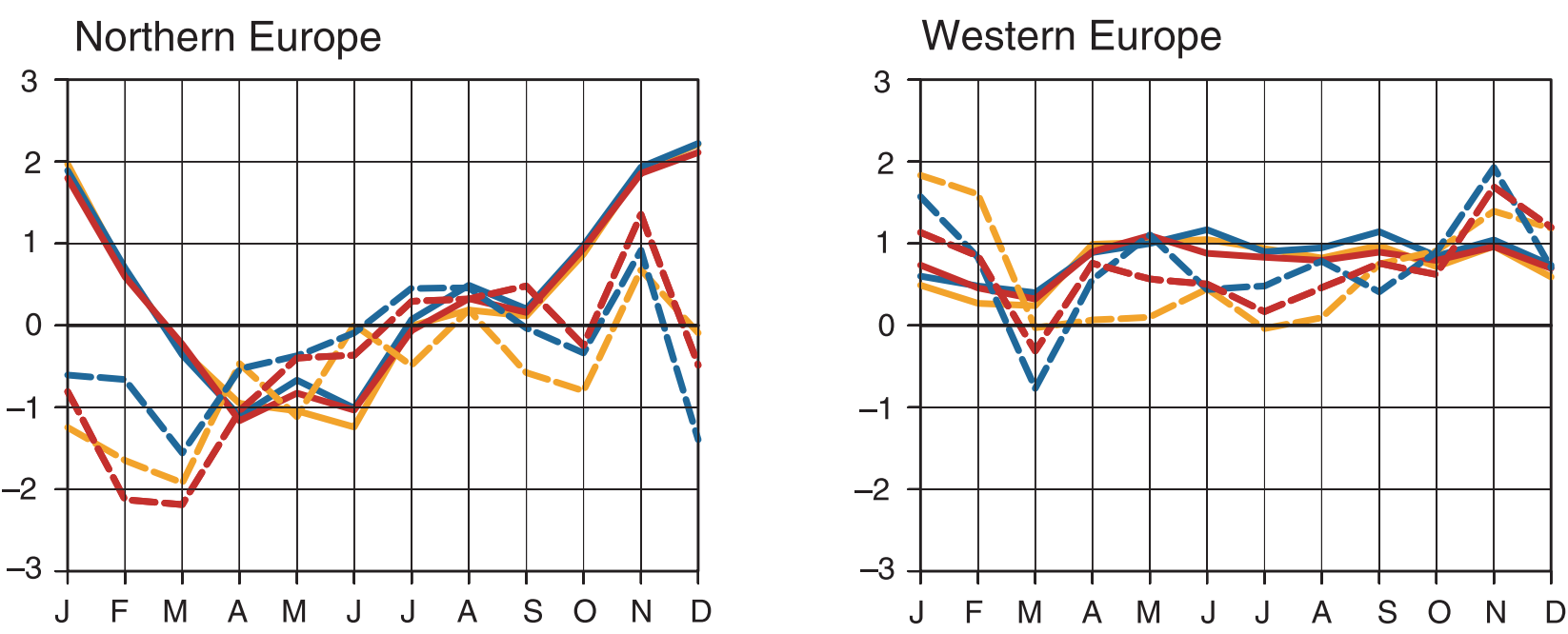

Central Europe

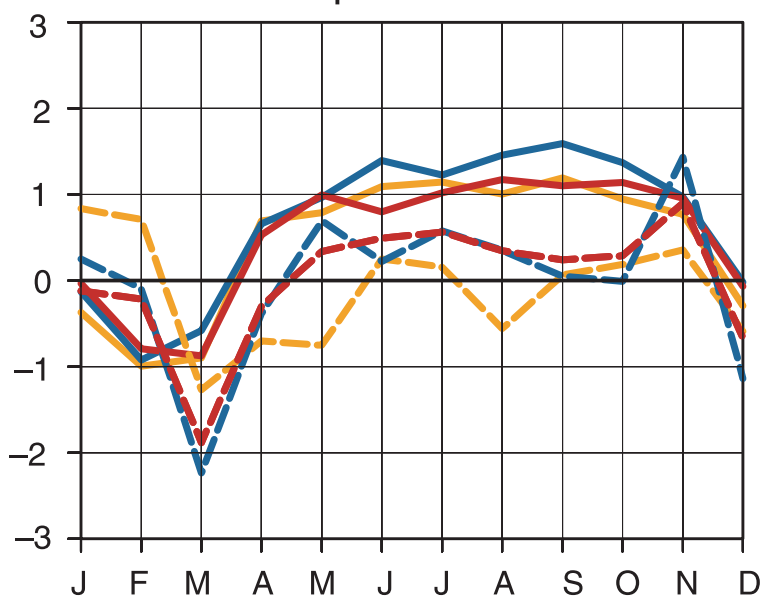

Eastern Europe

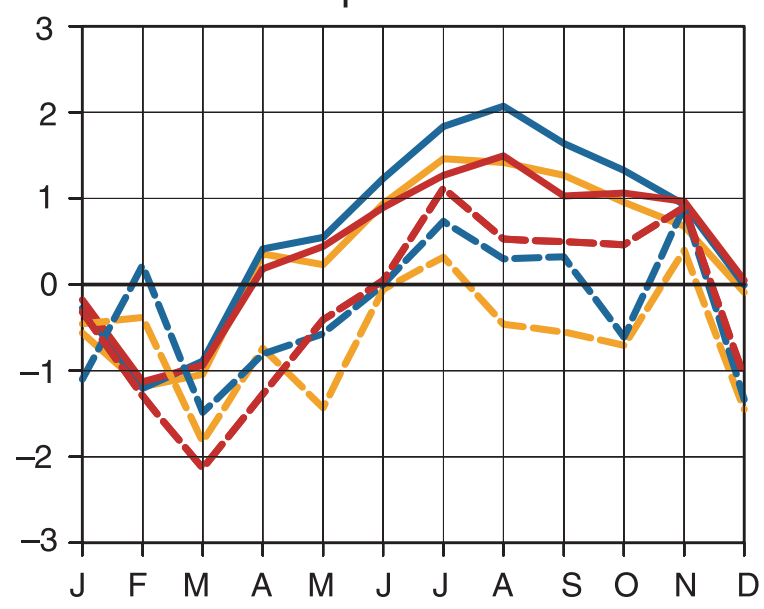

Southern Europe

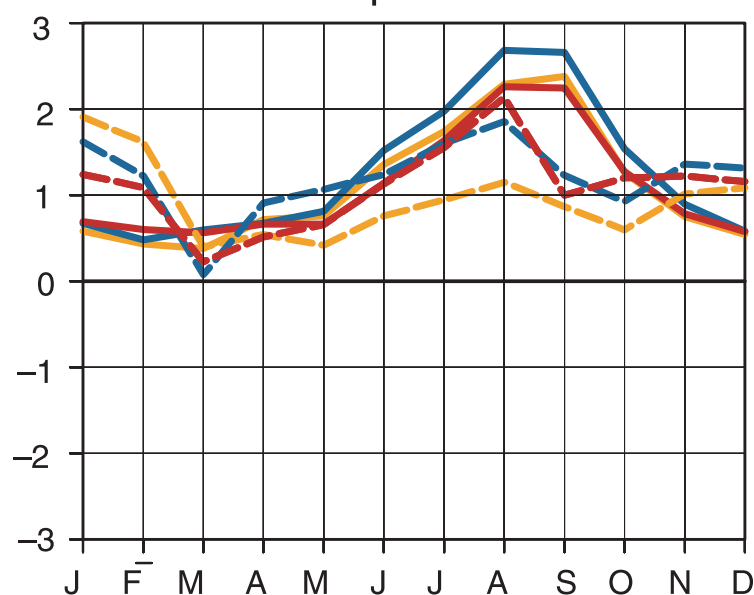

Model domain

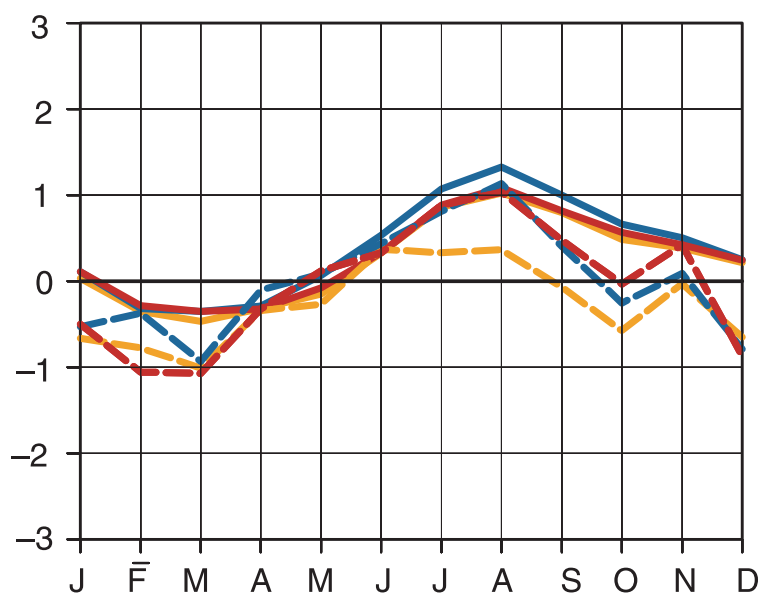

CONT EXP1

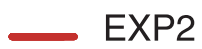

- CRU

Fig. 17. Annual cycles of $2 \mathrm{~m}$ temperature differences [K] 1979-1993 of the three model simulations compared to CRU observations (zeroline) for the global (dashed lines) and the regional (solid lines) sensitivity studies 
Precipitation [mm/month] 1979-1993

Northern Europe

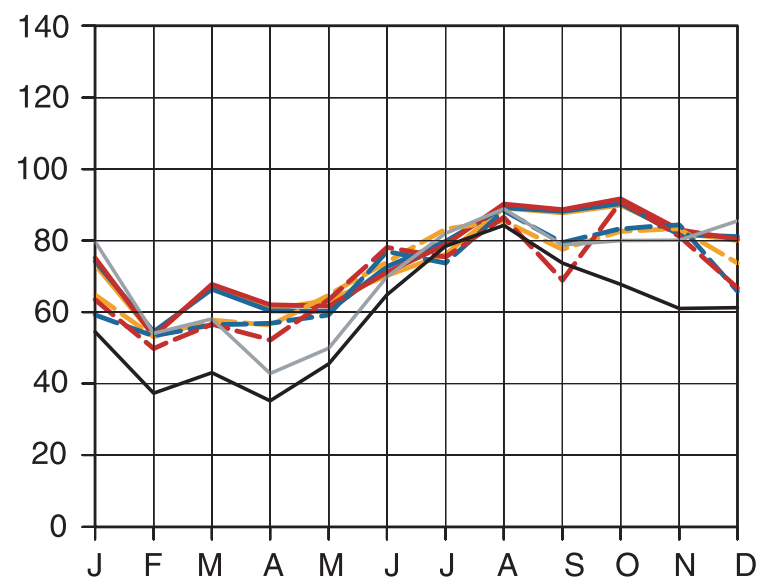

Central Europe

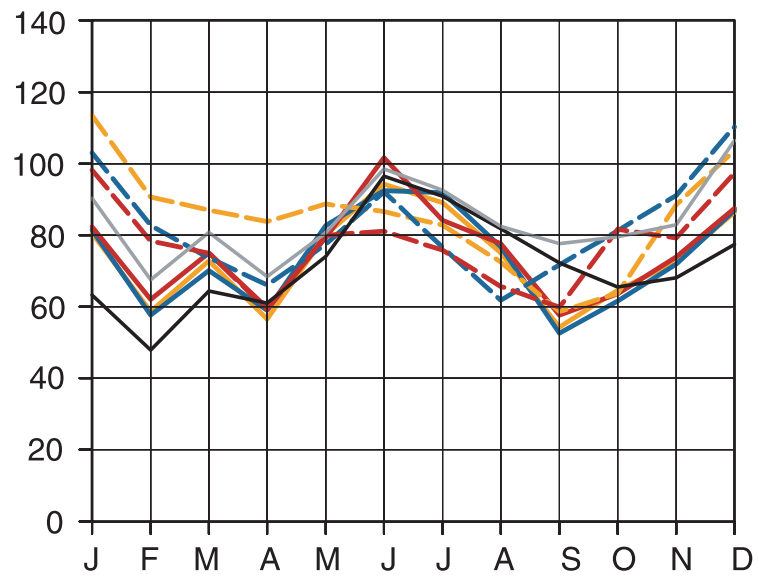

Southern Europe

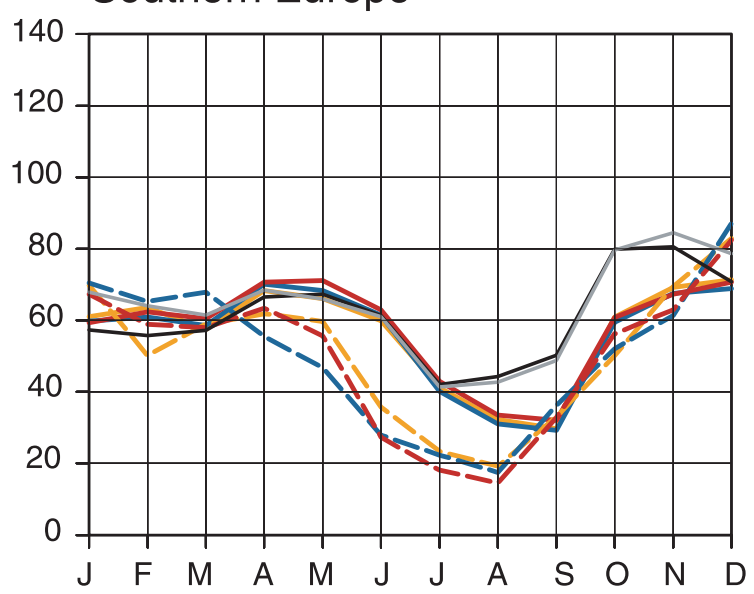

EXP1

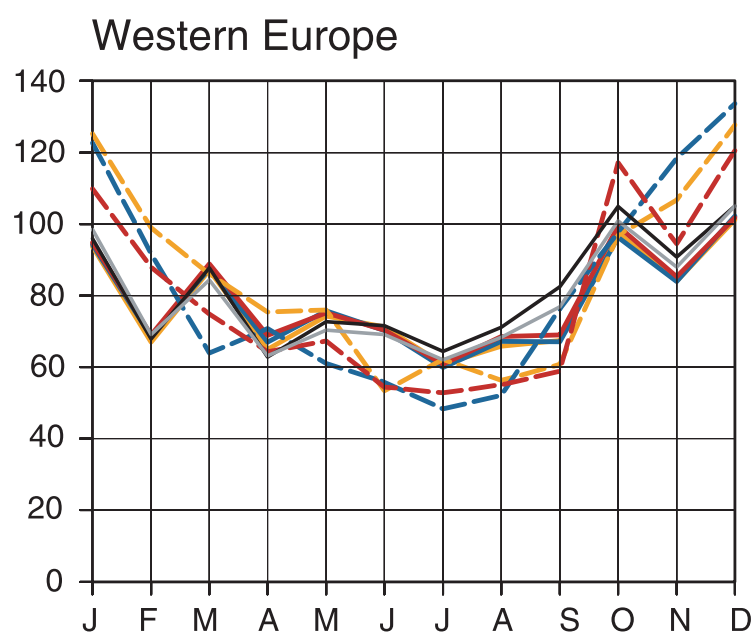

Eastern Europe

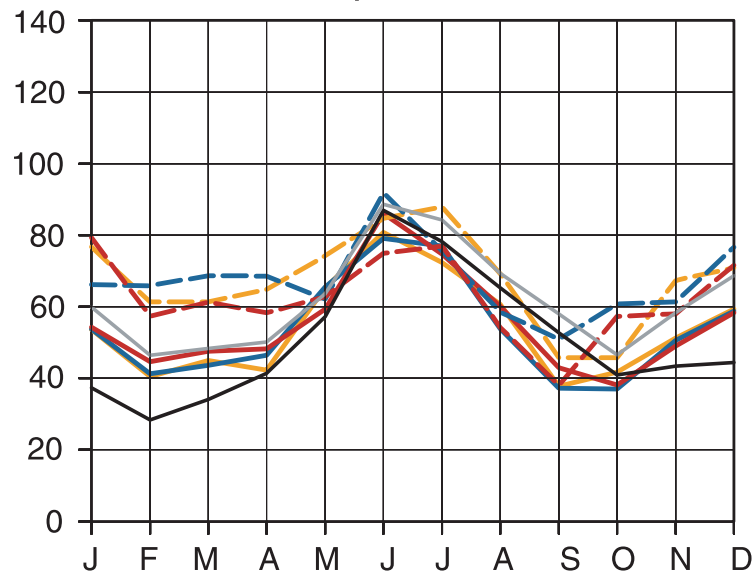

Model domain

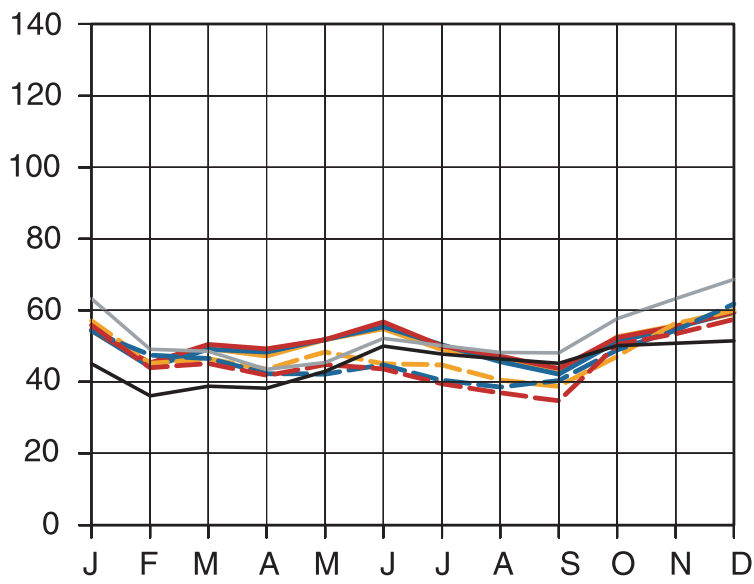

EXP2

$\mathrm{CRU}$

GPCP

Fig. 18. Annual precipitation cycles [mm/month] 1979-1993 of the three simulations for the global (dashed lines) and the regional (solid lines) sensitivity studies and of observations from CRU and GPCP 
tails can be seen. In Fig. 16 the differences of the mean annual cycles of precipitation between EXP2-EXP1, EXP2-CONT and EXP1-CONT are presented for the global (dashed lines) and the regional simulations (solid lines). Here again, in all selected European regions, the global results show a slightly higher sensitivity to the changed albedo parameterisation.

From the comparison of the regional and global model simulations we conclude that studies of land-use changes and their influence on the regional climate should be done on the global as well as the regional scale. The consistent global simulation can be used to drive the regional simulation at the lateral boundaries to consider the influence of changed land surface properties on the large scale circulation patterns. The regional simulation then is able to resolve local effects of changed land surface properties which are often superposed by large-scale effects in the global simulations.

\subsection{Comparison with observational data sets}

Observational datasets are extracted from the Climatic Research Unit analyses version 2.0 (CRU: New et al. 2000, Mitchell et al. 2004) and the Global Precipitation Climatology Project version 2.0 (GPCP: Huffmann et al. 1997). The CRU dataset provides global $2 \mathrm{~m}$ temperature and precipitation fields as time series of monthly means for the time period $1901-2000$ at a $0.5^{\circ}$ horizontal resolution for the land surface area. The temperature and precipitation fields are based on gauge measurements. The GPCP precipitation dataset is globally gridded data at a $2.5^{\circ}$ resolution based on gauge measurements over land and satellite data over sea. The GPCP precipitation values are corrected for undercatch of gauge stations. Time series of monthly means are available for 1979-2000. By using area averages we expect to reduce uncertainties in the observations that are caused by the location, exposure and altitude of the stations.

In Fig. 17 the simulated mean annual cycles of $2 \mathrm{~m}$ temperatures are presented as differences to the CRU observations (zeroline) area-averaged over the selected European regions for the regional (solid lines) and the global (dashed lines) simulations. In the regional simulations, except for northern Europe, in all regions the temperatures during summer and autumn are overesti- mated by up to $+2.5 \mathrm{~K}$ in southern Europe. In northern Europe the winter temperatures are overestimated by up to $+2 \mathrm{~K}$. The seasonal variability of the background surface albedo compensates the slightly worsened overestimation of summer temperatures caused by the lower mean background albedo of EXP1 compared to the control run. In the global simulations the summer and autumn temperatures are in better agreement with the observed values. In contrast to the regional results, the winter and spring temperatures in northern Europe are underestimated. Together, the temperature differences from the observations are larger than the differences between the three model simulations.

In Fig. 18 the mean annual cycles of the simulated precipitation are presented compared to the observational data from CRU and GPCP. The regional results are in better agreement with the observations than the global results. Here, the higher resolution of the regional model simulation shows its advantage in resolving orographical effects on precipitation. Especially in western, central and eastern Europe the regional simulated precipitation cycles closely agree with the observations. In northern Europe, the model simulations overestimate precipitation from October to May, especially when compared to the CRU data. In southern Europe the simulated precipitation is underestimated during late summer and autumn and in the global simulation this begins in spring. Between the three regional model experiments almost no differences exist. In contrast, the global simulation studies show larger differences to each other, but together the differences to the observations are larger than the differences between the model simulations. Thus, the sensitivity of the simulated temperature and precipitation to the changed albedo parameterisation lies within the uncertainty range of the simulated model results compared to the observation dataset used in this study. So, it is not possible to say if the new albedo parameterisation improves the model simulations with regard to temperature and precipitation.

\section{Conclusions and outlook}

An advanced parameterisation of the snow-free land surface albedo describing the monthly variation of surface albedo as a function of vegeta- 
tion phenology derived from MODIS data was integrated into the land surface schemes of the global climate model ECHAM5 and the regional climate model REMO. Three model simulations were performed, in order, to study the sensitivity of the simulated climate to the seasonal background albedo variability. The analysis of the simulation results demonstrates the influence of the new albedo parameterisation on the model simulations. The effect of the new mean background albedo superposes partly the effect of the seasonal albedo variability, which became evident while evaluating both effects separately. Strong effects occur over Europe, so it was an appropriate model domain for the regional simulation studies. In this region, the regional and the global model simulations respond differently to the new albedo parameterisation. In contrast to the global simulation, where the large-scale atmospheric conditions are changed by the new albedo parameterisation, the regional simulations circulation patterns within the model domain are not influenced. Here, the external forcing via the lateral boundaries of the regional model domain suppresses changes in the large-scale circulation that might occur without the external forcing. In the regional model simulations local effects mainly occur during the summer season, when the vertical energy exchange at the land surface is enhanced compared to the winter season with snow cover dominating the surface properties. In the global ECHAM5 simulations, the moderate albedo forcing during DJF causes strong changes in the analysed near-surface climate parameters. The effects on the simulated climate are not restricted to regions where land surface albedo is changed, but also occur in remote regions through atmospheric teleconnections. These remote climate impacts of the changed land surface albedo can only be explained by the modification of the planetary-scale atmospheric circulation. Initial attempts were made to reveal changes in the atmospheric circulation patterns. Further analysis of these atmospheric teleconnections would be very interesting, especially with regard to land cover change studies.

The comparison between the regional and global studies for the selected European regions found that the global results show a higher level of sensitivity of the annual temperature and precipitation cycles to the changed albedo parame- terisation. In the global simulations, the summer and autumn temperatures are in better agreement with the observations compared to the regional simulation results. For both the regional and the global study the temperature differences to the observations are larger than the differences between the three model simulations. For precipitation, the regional results are in better agreement with the observations than the global results. Here, the higher horizontal resolution of the regional model is beneficial in resolving the orographical effects on precipitation.

It is not possible to say if there is an improvement of the climate model simulations with regard to near surface temperature and precipitation compared to the observations on the continental scale investigated in this study. This could be investigated in further studies if the simulated model parameters show higher sensitivity to the changed land surface albedo scheme on smaller scales. Nevertheless, we can recommend the implementation of the new parameterisation scheme for the background surface albedo in climate models. The consideration of the seasonal surface albedo variations in climate simulations is more realistic for the representation of land surface processes and the new albedo scheme only marginally extends the computation time of the climate models. Moreover, the dynamic formulation of the background surface albedo as a function of the leaf area index is a first step on the way to a dynamic vegetation phenology scheme. The extension of the introduced albedo scheme to spatial vegetation changes will also enable advanced impact studies of land-use change, deforestation and desertification.

For the regional model REMO, Rechid and Jacob (2006) investigated the influence of vegetation phenology on the simulated climate in Europe. Compared to the results of this study, the sensitivity of the regional climate to the monthly varying leaf area index was larger than to the new albedo parameterisation, especially for precipitation. At this time a dynamic vegetation phenology scheme for the leaf area index as a function of the model's climate is in preparation to represent the interannual variability of vegetation phenology and its feedback to the simulated climate. The new albedo parameterisation introduced in this study will also be applied to this phenology scheme. 


\section{Acknowledgements}

We are very grateful to our colleagues of the MPI-M, especially to Monika Esch, Erich Roeckner, Thomas Raddatz, Susanne Pfeifer, Holger Göttel and Sven Kotlarski, for their cooperation and helpful discussions. Special thanks to the reviewers for their help in improving the manuscript.

\section{References}

Berbet MLC, Costa MH (2003) Climate change after tropical deforestation: seasonal variability of surface albedo and its effects on precipitation change. J Climate 116: 2099-2104

Betts RA (2001) Biogeophysical impacts of land use on present-day climate: near-surface temperature change and radiative forcing. Atmos Sci Lett 2, doi: 10.1006/ asle. 2000.0023

Burke EJ, Shuttleworth WJ, Yang ZL, Mullen SL, Arain MA (2000) The impact of the parameterization of heterogeneous vegetation on the modeled large-scale circulation in CCM3-BATS. Geophys Res Lett 27: 397-400

Chase TN, Pielke RA, Kittel TGF, Nemani RR, Running SW (2000) Simulated impacts of historical land cover changes on global climate in northern winter. Clim Dyn 16: 93-105

Dickinson RE, Hanson B (1984) Vegetation-albedo feedbacks. In: Hanson JE, Takahashi T (eds) Climate Processes and Climate Sensitivity. Geophys Monogr Ser, 29, AGU, Washington, D.C., pp 180-186

Dirmeyer PA, Shukla J (1994) Albedo as a modulator of climate response to tropical deforestation. J Geophys Res 99: 20,863-20,877

Eidenshink JC, Faundeen JL (1994) The $1 \mathrm{~km}$ AVHRR global land dataset: first stages in implementation. Int $\mathbf{J}$ Remote Sensing 15: 3443-3462

Hagemann S (2002) An improved land surface parameter dataset for global and regional climate models. Report 336, Max-Planck-Institute for Meteorology, Hamburg

Hagemann S, Botzet M, Dümenil L, Machenhauer M (1999) Derivation of global GCM boundary conditions from $1 \mathrm{~km}$ land use satellite data. Report 289, Max-Planck-Institute for Meteorology, Hamburg

Huffman GJ, Adler RF, Arkin A, Chang A, Ferraro R, Gruber A, Janowiak J, Joyce RJ, Mcnab A, Rudolf B, Schneider U, Xie P (1997) The Global Precipitation Climatology Project (GPCP) combined precipitation data set. Bull Amer Meteor Soc 78: 5-20

Jacob D, Podzun R (1997) Sensitivity studies with the regional climate model REMO. Meteorol Atmos Phys 63: 119-129

Jacob D, Andrae U, Elgered G, Fortelius C, Graham PL, Jackson SD, Karstens U, Koepken C, Lindau R, Podzun R, Rockel B, Rubel F, Sass HB, Smith RND, Van den Hurk BJJM, Yang X (2001) A comprehensive model intercomparison study investigating the water budget during the BALTEX-PIDCAP period. Meteorol Atmos Phys 77: 19-43

Lin ZH, Zeng QC, Ouyang B (1996) Sensitivity of the IAP two level AGCM to surface albedo variations. Theor Appl Climatol 55: 157-162

Lofgren BM (1995) Surface albedo-climate feedback simulated using two-way coupling. J Climate 8: 2543-2562
Mitchell TD, Carter TR, Jones PD, Hulme M, New M (2004) A comprehensive set of high-resolution grids of monthly climate for Europe and the globe: the observed record (1901-2000) and 16 scenarios (2001-2100). Working Pap. 55, Tyndall Cent., Norwich, UK

Myhre G, Myhre A (2003) Uncertainties in radiative forcing to surface albedo changes caused by land use changes. J Climate 16: 1511-1524

New M, Hulme M, Jones PD (2000) Representing twentiethcentury space-time climate variability. Part II: Development of 1901-96 monthly grids of terrestrial surface climate. J Climate 13: 2217-2238

Olson JS (1994a) Global ecosystem framework: definitions. USGS EROS Data Center Internal Report, Sioux Falls, $\mathrm{SD}, 37 \mathrm{pp}$

Olson JS (1994b) Global ecosystem framework: translation strategy. USGS EROS Data Center Internal Report, Sioux Falls, SD, 39 pp

Rechid D, Jacob D (2006) Influence of monthly varying vegetation on the simulated climate in Europe. Meteorol Z 15: 99-116

Rechid D, Raddatz TJ, Jacob D (2007) Parameterization of snow-free land surface albedo as a function of vegetation phenology based on MODIS data and applied in climate modelling. Theor Appl Climatol (in press)

Roeckner E, Bäuml G, Bonaventura L, Brokopf R, Esch M, Giorgetta M, Hagemann S, Kirchner I, Kornblueh L, Manzini E, Rhodin A, Schlese U, Schulzweida U, Tompkins A (2003) The atmospheric general circulation model ECHAM-5: Part I. Model description. Report 349, Max-Planck-Institute for Meteorology, Hamburg

Rowntree PR, Sangster AB (1986) Modelling the impact of land surface changes on Sahel rainfall. Rep. 9, World Climate Research Programme, Geneva

Sardeshmukh PD, Hoskins BJ (1987) The generation of global rotational flow by steady idealized tropical divergence. J Atmos Sci 45: 1228-1251

Sellers PJ, Randall DA, Collatz GJ, Berry JA, Field CB, Dazlich DA, Zhang C, Collelo GD, Bounoua L (1996a) A revised land surface parameterization (SIB2) for atmospheric GCMs: Part I. Model formulation. J Climate 9: 676-705

Sellers PJ, Los SO, Tucker CJ, Justice CO, Dazlich DA, Collatz GJ, Randall DA (1996b) A revised land surface parameterization (SIB2) for atmospheric GCMs: Part II. The gerneration of global fields of terrestrial biophysical parameters from satellite data. J Climate 9: 706-737

Song J (1999) Phenological influences on the albedo of prairie grassland and crop fields. Int J Biometeorol 42: $153-157$

Tanaka HL, Ishizaki N, Nohara D (2005) Intercomparison of the Intensities and Trends of Hadley, Walker and Monsoon Circulations in the Global Warming Projections. SOLA, 1, 77-80

US Geological Survey (1997) Global land cover characteristics data base. http://edcwww.cr.usgs. gov/landdaac/ glcc/globe_int.html

US Geological Survey (2002) Global land cover characteristics data base version 2.0. http://edcdaac.usgs.gov/ glcc/globedoc2_0.html 
Uppala SM, Kallberg PW, Simmons AJ, Andrae U, Bechtold VD, Fiorino M, Gibson JK, Haseler J, Hernandez A, Kelly GA, Li X, Onogi K, Saarinen S, Sokka N, Allan RP, Andersson E, Arpe K, Balmaseda MA, Beljaars ACM, Van De Berg L, Bidlot J, Bormann N, Caires S, Chevallier F, Dethof A, Dragosavac M, Fisher M, Fuentes M, Hagemann S, Holm E, Hoskins BJ, Isaksen L, Janssen PAEM, Jenne R, McNally AP, Mahfouf JF, Morcrette JJ, Rayner NA, Saunders RW, Simon P, Sterl A, Trenberth KE, Untch A,
Vasiljevic D, Viterbo P, Woollen J (2005) The ERA-40 Re-analysis. Quart J Roy Meteorol Soc, Oct 2005 Part B Zhou L, Dickinson RE, Tian Y, Zeng X, Dai Y, Yang ZL, Schaaf CB, Gao F, Jin Y, Strahler A, Myneni RB, Yu H, Wu W, Shaikh M (2003) Comparison of seasonal and spatial variations of albedos from Moderate-Resolution Imaging Spectroradiometer (MODIS) and Common Land Model. J Geophys Res 108(D15): 4488, doi: 10.1029/ 2002JD003326 